A Food and Agriculture Organization of the United Nations

\title{
Policy guide to improve water productivity in small-scale agriculture
}

The case of Burkina Faso, Morocco and Uganda 
Required citation:

Salman, M., Pek, E., Fereres, E. \& García-Vila, M. 2020. Policy guide to improve water productivity in small-scale agriculture - The case of Burkina Faso, Morocco and Uganda. Rome, FAO. https://doi.org/10.4060/CA7596EN

The designations employed and the presentation of material in this information product do not imply the expression of any opinion whatsoever on the part of the Food and Agriculture Organization of the United Nations (FAO) concerning the legal or deve lopment status of any country, territory, city or area or of its authorities, or concerning the delimitation of its frontiers or boundaries. The mention of specific companies or products of manufacturers, whether or not these have been patented, does not imply that these have been endorsed or recommended by FAO in preference to others of a similar nature that are not mentioned.

The views expressed in this information product are those of the author(s) and do not necessarily reflect the views or policies of FAO.

ISBN 978-92-5-132143-0

(C) FAO, 2020

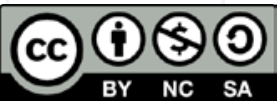

Some rights reserved. This work is made available under the Creative Commons Attribution-NonCommercial-ShareAlike 3.0 IGO licence (CC BY-NC-SA 3.0 IGO; https://creativecommons.org/licenses/by-nc-sa/3.0/igo/legalcode).

Under the terms of this licence, this work may be copied, redistributed and adapted for non-commercial purposes, provided that the work is appropriately cited. In any use of this work, there should be no suggestion that FAO endorses any specific organization, products or services. The use of the FAO logo is not permitted. If the work is adapted, then it must be licensed under the same or equivalent Creative Commons licence. If a translation of this work is created, it must include the following disclaimer along with the required citation: "This translation was not created by the Food and Agriculture Organization of the United Nations (FAO). FAO is not responsible for the content or accuracy of this translation. The original [Language] edition shall be the authoritative edition."

Disputes arising under the licence that cannot be settled amicably will be resolved by mediation and arbitration as described in Article 8 of the licence except as otherwise provided herein. The applicable mediation rules will be the mediation rules of the World Intellectual Property Organization http://www.wipo.int/amc/en/mediation/rules and any arbitration will be conducted in accordance with the Arbitration Rules of the United Nations Commission on International Trade Law (UNCITRAL).

Third-party materials. Users wishing to reuse material from this work that is attributed to a third party, such as tables, figures or images, are responsible for determining whether permission is needed for that reuse and for obtaining permission from the copyright holder. The risk of claims resulting from infringement of any third-party-owned component in the work rests solely with the user.

Sales, rights and licensing. FAO information products are available on the FAO website (www.fao.org/publications) and can be purchased through publications-sales@fao.org. Requests for commercial use should be submitted via: www.fao.org/contact-us/licence-request. Queries regarding rights and licensing should be submitted to: copyright@fao.org. 


\section{Policy guide to improve water productivity in small-scale agriculture}

The case of Burkina Faso, Morocco and Uganda

By

Maher Salman,

Senior Land and Water Officer, FAO

Eva Pek,

FAO Consultant

Elias Fereres \& Margarita García-Vila, University of Cordoba, Spain

With contributions from:

Stefania Giusti,

FAO Consultant

Fethi Lebdi,

FAO Consultant

Ángel F. González-Gómez, University of Cordoba, Spain

FOOD AND AGRICULTURE ORGANIZATION OF THE UNITED NATIONS

Rome, 2020 


$$
\text { Ifillin }
$$




\section{Contents}

Foreword

Acknowledgements

Acronyms

viii

Introduction: producing more with less

What are the water productivity instruments?

3

Concept of water productivity and its implication

Water productivity concept

How Water Productivity evolved through the project:

the organization of the guidelines

Policy guidelines for improving water productivity in Burkina Faso, Morocco and Uganda

Water use efficiency to meet Strategic Development Goals, strategic objectives and the global water policy objectives

Understanding the country focus:

key features and national policies affecting water productivity

Burkina Faso

Morocco

Uganda

Key achievements in water productivity for designing policy instruments

Burkina Faso: staple crop vs. cash crops

Morocco: coping with water scarcity 
Synthesis of policy recommendations

Conclusion 55

Bibliography 56 


\section{Foreword}

The achievement of the Sustainable Development Goals (SDGs) is at risk as countries worldwide are confronted with new challenges in their efforts to build a world without hunger, food insecurity and malnutrition. Among these are the increasing water scarcity and unprecedented global water crises, not only related to the changing climate. Water-related issues are expected to significantly affect countries' development over the next several decades and, if not addressed correctly and in due time, could bring dramatic consequences for the conservation and sustainability of ecosystems, the equality and fairness of economic growth, and, ultimately, for the possibility to reduce poverty and hunger.

The challenge to boost food production in order to meet the quality and quantity needs of the growing population is likely to intensify and thus requires innovative and context-tailored solutions. Irrigated agriculture, in its role, on one side, as a major contributor to the expansion of food supplies at global scale and, on the other, as the largest consumer of water resources in developing countries can provide a key contribution in enhancing food production while at the same time reducing employed resources.

Efforts to strengthen water productivity in agriculture are largely recognized as a successful strategy within the Integrated Water Resources Management (IWRM) approach, whereby even small improvements could have significant impacts in water budgets. Along this line, a growing number of relevant international institutions are indicating the increase of agricultural water productivity as a policy goal of paramount importance. In 2000, the Global Water Partnership set a target of a 30 percent increase in water productivity for food production to be achieved by 2015 and in that same year, the World Water Council predicted that enhanced water productivity would allow to meet half of the increased water demand for agriculture by 2025 .

These objectives appear to be even more crucial when considering the still predominant rainfed agriculture in developing countries (around 60 percent of production) as compared to the significant opportunities to expand agricultural irrigation. Nevertheless, public communications and outreach products often still miss to correctly explain the lines of actions that should be pursued and the practices that should be implemented at field level to consistently enhance agricultural production while trying not to exacerbate water scarcity.

The "Strengthening Agricultural Water Efficiency and Productivity at the African and Global Level" project aimed at overcoming these challenges, firstly, through the diagnosis of the current levels of water productivity and thus introducing improved management practices in selected pilot sites for different crops. The present Guide takes into consideration the high heterogeneity of smallscale irrigation schemes, as those addressed by the project, to draw conclusions and formulate 
recommendations that recognize the importance of water productivity-related policies and foster the inclusion in national relevant frameworks of adequate financial, social and logistics instruments, in support of small-scale agriculture and smallholders. 


\section{Acknowledgements}

The Policy Guide to improve Water Productivity in Small Scale Agriculture is the joint effort of the Land and Water Division of FAO (CBL) and of the University of Cordoba, Spain (UCO).

The Policy Guide is based on the results of the FAO Project "Strengthening Agricultural Water Efficiency and Productivity at the African and Global Level" funded by the Swiss Agency for Development and cooperation (SDC).

The authors of this Policy Guide are Maher Salman and Eva Pek from FAO; and Elias Fereres and Margarita García-Vila from the University of Cordoba.

The authors gratefully acknowledge the guidance received from Eduardo Mansur, Director of Land and Water Division of FAO, and the contribution of Fethi Lebdi, Stefania Giusti and Ángel F. González-Gómez.

A special thanks to James Morgan for the design. 


\section{Acronyms}

AAA

ABH

AMMS

AMSP

AMVS

ASSP

AWM

CAADP

COMESA

CSLP

DGPER

DI

EAC

ECOWAP

ECOWAS

ET

ETc

EU

FAO

GDP

IGAD

INERA

INRA

IRRI

IWRM

MAAH

MAAIF

MAPMDREF

MDG

MWE

NAIP

NAP
Adaptation of African Agriculture

Agence de Bassin Hydraulique (River Basin Agency) - Morocco

Association Marocaine des Multiplicateurs de Semences (Moroccan Association of Seed Multipliers)

Association Marocaine des Semences et Plants (Moroccan Association of Seeds and Plants)

Autorité de Mise en Valeur de la Vallée du Sourou (Sourou Valley Development Authority) Burkina Faso

Agriculture Sector Strategic Plan - Uganda

Agricultural Water Management

Comprehensive Africa Agriculture Development Programme

Common Market for East and Southern Africa

Cadre Stratégique du Lutte Contre la Pauvreté (Strategic Framework to Combat Poverty) - Burkina Faso

Direction générale de la promotion de l'économie rurale (General Directorate for the Promotion of the Rural Economy) - Burkina Faso

Deficit irrigation

East African Community

Regional Agricultural Policy for West Africa

Economic Community of West African States

Evapotranspiration

Crop evapotranspiration

European Union

Food and Agriculture Organization

Gross Domestic Product

Intergovernmental Authority on Development - Uganda

Institut de l'Environnement et Recherches Agricoles (Institute of Environment and Agricultural Research) - Burkina Faso

Institut national de la recherche agronomique (National Institute of Agronomic Research) Morocco

International Rice Research Institute

Integrated Water Resource Management

Ministère de l'Agriculture et des Amenagements Hydro-agricoles - Burkina Faso (Ministry of Agriculture and Hydraulic Development - Burkina Faso)

Ministry of Agriculture, Animal Industry and Fisheries - Uganda

Ministère de l'Agriculture, de la Pêche Maritime, du Développement Rural et des Eaux et Forêts Maroc (Ministry of Agriculture, Fisheries, Rural Development, Water and Forests - Morocco)

Millennium Development Goal

Ministry of Water and Environment - Uganda

National Agricultural Investment Plan

National Agriculture Policy 
National Development Plan

NENA

Near East and North Africa

NEPAD

New Partnership for Africa's Development

NERICA

New Rice for Africa

ONCA

Office National du Conseil Agricole - Maroc (National Office of Agricultural Council - Morocco)

ONSSA Office national de sécurité sanitaire des produits alimentaires - Maroc (National Office of Food Safety - Morocco)

ORMVA Office Régional de Mise en Valeur Agricole (Regional Organization of Agricultural Development) - Morocco

ORMVAH Office Régional de Mise en Valeur Agricole du Haouz (Regional Office of Agricultural Development of Haouz) - Morocco

PMV Plan Maroc Vert (Green Morocco Plan)

PNDES

Plan national de développement économique et social-- Burkina Faso (National Economic and Social Development Plan - Burkina Faso)

PNE Partenariat National de I'Eau (National Water Partnership) - Burkina Faso

PNEEI

PNSR Programme National d'Economie d'Eau en Irrigation (National Programme for Saving Water in Irrigation) - Burkina Faso

Programme National du Secteur Rural (National Programme for the Rural Sector - Burkina Faso) - Burkina Faso

PRIA Programme régional d'investissements agricoles (Regional Agricultural Investment Plan) - Burkina Faso

SDG Sustainable Development Goal

SDR Stratégie de Développement Rural (Rural Development Strategy) - Burkina Faso

SNAT Schéma National d'Aménagement du Territoire - Maroc

SNE Stratégie Nationale de l'Eau (National Water Strategy) - Maroc

SNSA Stratégie Nationale de Sécurité Alimentaire (National Food Security Strategy) - Burkina Faso

SONACOS Société Nationale de Commercialisation des Semences (National Seed Marketing Company) Maroc

TAW Total Available soil Water

UAA Utilised Agricultural Area

UBOS Uganda Bureau of Statistics

UNFCCC United Nations Framework Convention on Climate Change WP Water Productivity

WUA Water User Association

WUE Water Use Efficiency 


$$
\text { istur }
$$




\section{Introduction: producing more with less}

Growing population with changing dietary pattern is the driving factor of increasing water demand in agriculture. Combined with limited natural resources, energy costs and forecasted impacts of climate change, the productive use of water is of paramount importance. Beyond the pressing issue of supplying global food demand, difficult trade-off occurs between the objectives of agricultural productivity growth and natural resources conservation.

Irrigation plays a critical role in transition from subsistence to commercial farming, poverty alleviation and economic growth. Irrigation can provide higher yields compared to the adjacent rainfed areas. Combined with suitable measures such as education, rural markets and infrastructure, irrigation generates also direct benefits other than productivity (increased profitability, reduced risk of crop failure and stabilization of local food production, fairer access to water resources) as well as indirect benefits (employment, additional income, balanced conditions of food and supply markets).

On average, agriculture-including irrigation, livestock and aquaculture-is the largest water user with 70 percent of the world's freshwater withdrawal. However, the share of agricultural water withdrawal differs amongst countries depending mostly on climatic conditions and the weight of agriculture in national economies. It ranges from 21 percent of the total water withdrawal in Europe to over 80 percent in Asia and Africa, reaching 90 percent in low-income countries (Figure 1). Therefore, increasing the productivity of agricultural water use in a sustainable manner is essential to, ultimately, sustain the social and economic conditions of livelihoods.

Figure 1: Water withdrawal ratios by continent

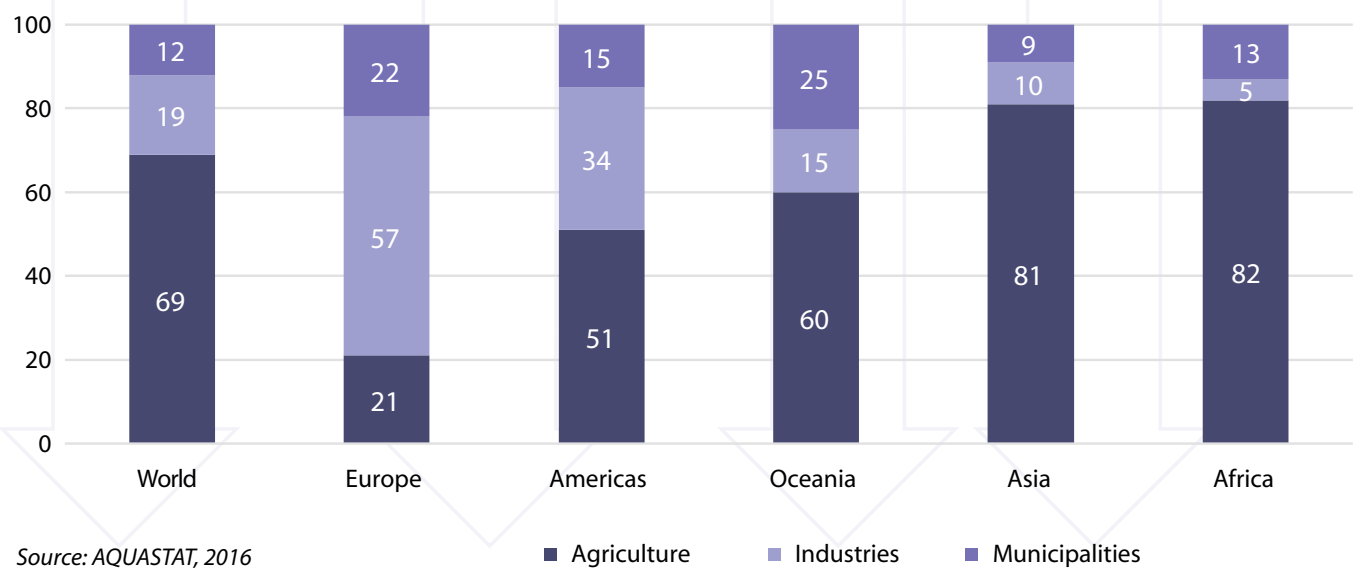


In developing countries, further progress of irrigation is essential for increasing food security and farmers' income. However, developing small-scale schemes remains a challenge due to the multiple factors that must be taken into consideration. The high diversity of small-scale schemes, the large number of water users, the social disharmony over water use, the varying water demands of multicropping systems and the heterogeneity of equipment over the scheme - all represent relevant issues influencing the development of small-scale irrigation systems. Furthermore, on-farm irrigation development has a major role in enhancing Agricultural Water Management (AWM), beyond improving the conveyance system. The previous development methods considered the improvement of single-factor productivity. Agriculture is currently undergoing a global shift from the single objective of farming outputs (such as yield or net income) to multiple objectives of increasing outputs while conserving natural resources.

Many pathways towards the enhancement of Water Productivity (WP) are directly related to improving overall farm agronomic management (irrigation, fertilization, plant density, plant protection, etc.), while external measures must be taken into consideration to ensure the sustainability of introduced good practices (lack of input markets, scarce knowledge, poor condition of infrastructures, water regulations, etc.). Thus introducing irrigation practices to farmers must undergo a step-wise process to ensure that costs do not outweighed achievable benefits, and both institutional and technical environment are capable to sustain results. This is the case in smallholders' schemes in particular, where farmers are poorly resourced and access to relevant information is cumbersome. In order to address these issues, the current policy guide presents a combined methodology, which involves practical experiences drawn from FAO work in the three countries as well as researches' results to line up a set of feasible measures to improving WP.

Under the framework of FAO project 'Strengthening Agricultural Water Efficiency and Productivity on the African and Global Level', the guide presents the key steps overarching the country-specific implementation of development programme and introduces designed WP instruments (WPis) in order to provide support to policy makers to enhance WP while entailing positive impact on agricultural production and efficient water use. For this purpose, the key role of WP and how it is improved at different scales is demonstrated, as well as existing policy frameworks on water and agriculture. These identified measures can be scaled-up by being offered to policy and decision makers aiming at improving national small-scale irrigation systems in other countries in Africa - or the rest of the world -, therefore setting a starting point for the wide acceptance of improvement measures. 


\section{What are the Water Productivity Instruments (WPI)?}

Defining the term "policy" is a complex task, which requires some flexibility for the permeability between the sectors. In simple term, policy is a formal process or plan for an action to achieve a particular goal. The form of policy varies on a wide range, for example, it can be economic or regulatory. However, the Guide does not consider policy as a linear process consisting of series of steps ("policy cycle"), but rather an iterative process commuting between stakeholders.

The policy formulation goes back and forth between decision-makers and end-users. Breaking down the process into particular means and tools to achieve policy goals is called policy instruments. Policy instruments are usually combined to create pathways to reach these goals. Five major types of policy instruments are differentiated: legislative and regulatory instruments, economic and fiscal instruments, agreement-based or co-operative instruments, information and communication instruments, and knowledge and innovation instruments. Instrument selection must consider generic criteria and summarize the impact of the instrument (Delacámara, 2013). The measured endorsement of instruments should be always inclusive, though, they also need to allow for externalities (interference with other sectors, out-of-system effects, necessary trade-offs, etc.).

The key characteristic of the instruments is that they create a bridge between legislation/framework and implementation. Therefore, WPIs were established on combined approaches throughout the project cycle: (1) review and process of existing policies, institutions and frameworks, and (2) experiences drawn from the field implementation. The combined approach helps not only to collect possible instruments, but also to design them to address the specific issues concerning AWM. The complementarity between existing policy frameworks and field experiences ensures the adaptability of the instruments then. The formulation of WPIs involves sequential steps presented in Figure 2. 
Figure 2: The flowchart of designing WPIs through the project cycle

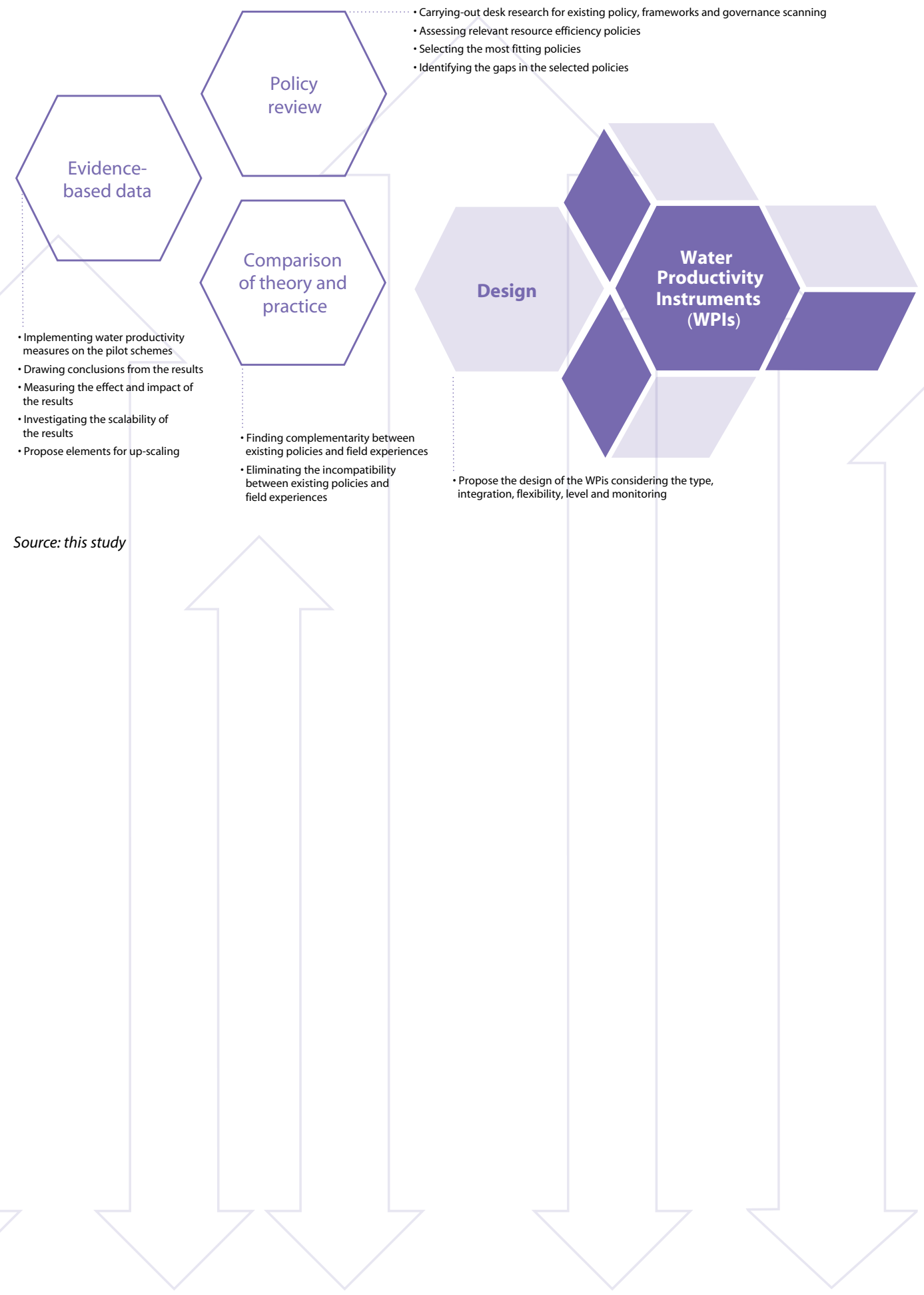




\section{Concept of Water Productivity and its implication}

\section{WP concept}

In water scarce areas or with high competition over resources, rather than increasing productivity per land area unit, the primary goal should be to sustainably increase production per water unit. Thus, the concept of water productivity emerges along the lines of assessing the efficiency of water use in crop production. WP is defined in agriculture as the ratio between the output and the amount of water to produce it, whereas the output can be measured in weight, value, and net profit (after deducing the production costs), while water amount can be expressed as water delivered, water supply and water consumed as evapotranspiration (ET). In a broader sense, additional outputs may be related to improved livelihoods, higher employment rates, reduced environmental costs or enhanced ecological benefits.

The WP analysis can be applied at different scales or levels according to the objectives of the improvement. The selection of the right variables of WP indicators varies depending on the expected results, as shown in Table 1.

Table 1: Water productivity interests at different scales

\begin{tabular}{|c|c|c|c|c|c|}
\hline & $\begin{array}{l}\text { Crop, plant, or } \\
\text { animal }\end{array}$ & Field or pond & $\begin{array}{l}\text { Farm or } \\
\text { agricultural } \\
\text { enterprise }\end{array}$ & Irrigation system & $\begin{array}{l}\text { Basin and } \\
\text { landscape }\end{array}$ \\
\hline Processes & $\begin{array}{l}\text { Energy } \\
\text { conversion, } \\
\text { nutrient uptake } \\
\text { and use, } \\
\text { photosynthesis, } \\
\text { and the like }\end{array}$ & $\begin{array}{l}\text { Soil, water, } \\
\text { nutrient } \\
\text { management }\end{array}$ & $\begin{array}{l}\text { Balancing risks and } \\
\text { rewards, managing } \\
\text { farm inputs } \\
\text { including water }\end{array}$ & $\begin{array}{l}\text { Distribution of } \\
\text { water to users, } \\
\text { operation and } \\
\text { maintenance, fees, } \\
\text { drainage }\end{array}$ & $\begin{array}{l}\text { Allocation } \\
\text { across uses, } \\
\text { regulation of } \\
\text { pollution }\end{array}$ \\
\hline Interests & $\begin{array}{l}\text { Agricultural } \\
\text { producers, } \\
\text { breeders, plant } \\
\text { and animal } \\
\text { physiologists }\end{array}$ & $\begin{array}{l}\text { Agricultural } \\
\text { producers; } \\
\text { soil, crop, } \\
\text { fish, livestock } \\
\text { scientists }\end{array}$ & $\begin{array}{l}\text { Agricultural } \\
\text { producers, } \\
\text { agriculturalists, } \\
\text { agriculture } \\
\text { economists }\end{array}$ & $\begin{array}{l}\text { Irrigation } \\
\text { engineers, social } \\
\text { scientists, water } \\
\text { managers }\end{array}$ & $\begin{array}{l}\text { Economists, } \\
\text { hydrologists, } \\
\text { social } \\
\text { scientists, } \\
\text { engineers, } \\
\text { water } \\
\text { managers }\end{array}$ \\
\hline
\end{tabular}




\begin{tabular}{|c|c|c|c|c|c|}
\hline \multirow[t]{3}{*}{$\begin{array}{l}\text { Production } \\
\text { terms } \\
\text { (numerator) }\end{array}$} & $\begin{array}{l}\text { Weight of } \\
\text { production }\end{array}$ & $\begin{array}{l}\text { Weight of } \\
\text { production }\end{array}$ & $\begin{array}{l}\text { Weight of } \\
\text { production, } \\
\text { economic value }\end{array}$ & $\begin{array}{l}\text { Weight of } \\
\text { production, } \\
\text { economic value, }\end{array}$ & $\begin{array}{l}\text { Economic } \\
\text { value, } \\
\text { ecosystem }\end{array}$ \\
\hline & & & & ecosystem & $\begin{array}{l}\text { services, other } \\
\text { values }\end{array}$ \\
\hline & & & & $\begin{array}{l}\text { services, other } \\
\text { values }\end{array}$ & \\
\hline \multirow[t]{2}{*}{$\begin{array}{l}\text { Water terms } \\
\text { (denominator) }\end{array}$} & Transpiration & \multirow[t]{2}{*}{$\begin{array}{l}\text { Transpiration, } \\
\text { evaporation, } \\
\text { water applied }\end{array}$} & \multirow[t]{2}{*}{$\begin{array}{l}\text { Evapotranspiration, } \\
\text { irrigation supply }\end{array}$} & $\begin{array}{l}\text { Irrigation } \\
\text { deliveries, } \\
\text { depletion, }\end{array}$ & $\begin{array}{l}\text { Deliveries, } \\
\text { flows, }\end{array}$ \\
\hline & & & & available water & depletion \\
\hline
\end{tabular}

Adapted from: Molden et al. (2007)

The key objectives of enhancing WP at plant, field and basin level, which apply regardless of whether the crop is grown under rainfed or irrigated conditions, are: 1) increase the yield or benefits, namely the marketable part of the crop for each unit of water transpired; 2 ) reduce any unnecessary "losses" (e.g. drainage, seepage and percolation), with the exception of the crop transpiration and special needs; and 3) increase the effective use of rainfall, stored water, and of water of marginal quality. The first objective relates to the need of increasing crop yields or values. The second and third objectives are part of the IWRM approach at basin level, whereby institutions and policies have the responsibility to ensure that the interventions carried out upstream have no adverse effect on downstream water users. These three objectives apply at all scales, from plant to field and to the agro-ecological system, but bringing them to the ground requires customized methodologies and measures. Since application of WP differs according to context, the number of methods for enhancing WP is ample. To understand the significance of WP, it is essential to follow the flow of water throughout the basin and to perceive how water supports life and livelihoods.

It starts at plant level with plant breeding. In this respect, improving seedling vigour, increasing rooting depth, increasing harvest index and strengthening photosynthetic efficiency are all viable ways to increase WP. The most significant improvements in yield stability aim to establish an appropriate growing cycle, which ensures sufficient water supply both in vegetative and reproductive periods. Drought escape and increasing drought tolerance are also important strategies for increasing WP.

Improved practices at field level concern changes in crop, soil and water management, such as appropriate crop selection and cultivars, plant density, crop protection, controlled irrigation, nutrient management, and improvement of drainage for water table control. In addition, a relevant number of external factors exist that have a strong influence on WP and on farmers' livelihoods. For instance, the WP gaps may be the result of the farmers' weak access to inputs due to poor market conditions, lack of knowledge and training opportunities (especially in the case of women), ineffective water regulations and unfair irrigation water supply, among other reasons. 
At system and river-basin level, the relative importance of different water management processes changes. Indeed, this scale does not consider only production issues, but also the effect of agriculture on other water users, i.e. human health and the environment. Opportunities to improve WP at agro-ecological or river-basin level can derive, amongst others, from enhanced land-use planning, agreements on shared uses amongst systems or countries, more effective use of medium-term weather forecasts, improved irrigation scheduling to account for rainfall variability, and conjunctive management of various sources of water, including water of poorer quality where appropriate. Gains in WP can be obtained by providing more reliable irrigation supplies, such as on-demand delivery of irrigation supplies. However, WP strategies must allow flexibility to create trade-off between competing water demands.

\section{To keep in mind}

Over the last 30 years, WP at river-basin level has evolved towards a cross-sectoral approach, in which trade-offs are more difficult to reach due to the large number of stakeholders and competing sectors. At the same time, the increasingly frequent interventions to enhance efficiency and productivity led to their inappropriate interpretation and application. Simple estimation of WP does not provide sufficient information on the possible effects of interventions. Adequate interpretation is required to understand the results in local contexts. Estimates of WP, by themselves, do not provide the information needed to fully understand the production opportunities, constraints and livelihood considerations that lie in a particular area. Comparing point observations of WP across locations and over time can be misleading, since they do not improve the understanding of farm-level water management in a manner that would guide policy makers towards wise interventions and investments.

Several farm water management practices, such as pressurized irrigation, are intended to convert more of the water input into transpiration to increase yield and, consequently, to reduce water losses. However, improving farm management and irrigation practices require the knowledge about the system-in-whole. To know if the most accurate farm management and irrigation practices "saves" water that can be used downstream, it is important to know what happens to the drainage flows. Drainage flows are non-recoverable in situations where water flows to a saline aquifer, or contributes to waterlogging. But drainage flows may be recoverable, when they are a source of water for downstream farmers, recharge the shallow groundwater for home orchards and domestic wells, or support other important ecosystem services. Misguided investments to "save" water in such cases can be detrimental to livelihoods and the economy.

Thus, the assessment of needs to increase the WP must be customized, depending on their water resources endowment and level of development. In addition, the analysis of production settings must apply a system-wise perspective, including information acquisition and interactions amongst inputs, and promote strategies that acknowledge the system-in-whole.

FAO defines WP as the crop yield produced per unit of evaporated water and it represents a key indicator of agricultural water management. The improvement of this indicator has been widely described as 'more crop per drop' or 'more sustainable livelihoods per drop'. 
Definition of WP is particularly meaningful and applicable in developing countries, where there is a shortage of water or economic water scarcity, i.e. where there is strong competition among sectors over water resources, even though they may be abundant at times. All measures for WP improvement must be considered, from the water application methods to all facets of agronomic management, all tailored to the specific situation of the agricultural system under consideration.

\section{Assessment of the potential increase in water productivity}

In order to identify WP improvement, it is necessary to determine the baseline or current status of WP in a given system (herein called "actual WP") and the maximum or attainable WP value that can be achieved under these specific conditions.

It should be noted that the relationship between land and water productivity in most crops follows a curve such as shown in Figure 3. Therefore, an increase in production at low levels leads to an increase in water productivity. However, in the range of high production values, increasing crop production or yield often means a decrease in water productivity. In these cases, the farmer will only find the motivation to sacrifice an increase in yield within a given plot if he/she obtains "extra water" for other more demanding or rewarding crops or if he/she can increase his land area under irrigation, which will increase the WP at farm level.

\section{Figure 3: Crop land productivity-crop} water productivity function

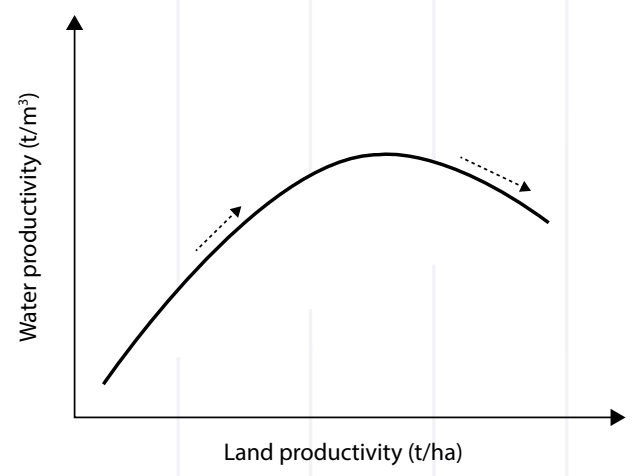

The potential for WP improvement can be quantified by using the WP gap concept, defined as the difference between attainable and actual WP. Figure 4 illustrates the process from WP gap identification to decision-making.

For these reasons, it is important to perform a detailed analysis of WP gaps at country level. The agricultural productivity gap observed in many irrigation schemes is closely related to the WP gap, particularly in water scarce areas or in areas with high competition. In most African countries, farmers do not exploit the potential benefits of irrigation; thus, there are many opportunities to improve on-farm WP, since it is below the attainable levels for the majority of crops. 
WATER PRODUCTIVITY
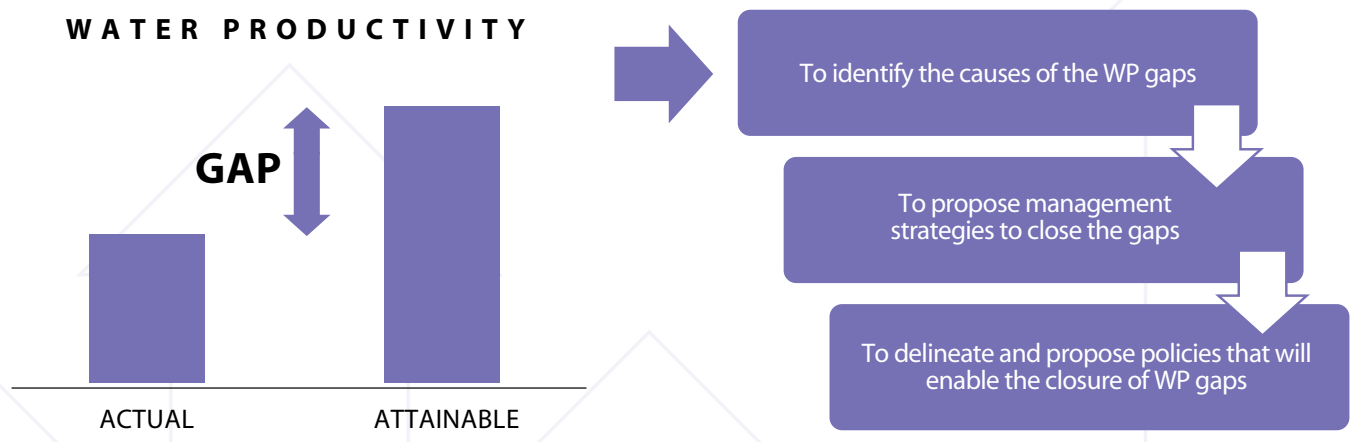

Source: this study

\section{How water productivity evolved through the project: the organization of the guidelines}

Water productivity is a result of farmers' agronomic practices and management of irrigation systems on a daily basis. Thus, a clear understanding of performed practices is required, focusing on: (i) current level of farmers' WP; (ii) achievable level of WP; and, (iii) effective means of reaching the achievable level of WP. This task is not simple since WP is affected and conditioned by multiple factors at different scales, of which several have only indirect link with water sector.

Drawing on the activities performed under the framework of the project, The Guide aims to provide key messages for policy makers in order to improve WP, with the overall objective of achieving a positive impact on agricultural production and on the conservation of water resources. The ultimate goal is to create an enabling environment for irrigated agriculture which allows for the optimization of farming practices to achieve increased WP. A comprehensive approach was adopted through the application of practical tools to enhance the small-scale farming conditions in three pilot schemes in Burkina Faso, Morocco and Uganda (Figure 5). The impact of these actions were investigated then to up-scale the lessons learnt.

\section{General data collection}

The collection of available data on the selected irrigation schemes was the initial step to perform a diagnosis of the current agricultural productivity levels and identify the limiting causes. Accordingly, desk review and data collection protocol were carried out including soil and climate information, water resources, cropping patterns, agronomic practices, main stakeholders and institutions, and relevant projects undertaken. The information was verified by local stakeholders and gaps were identified. Data collection programme included a stakeholder consultation to assess the major constrains and factors influencing crop WP and identify further information yet 
Figure 5: Schematic framework of the water productivity approach
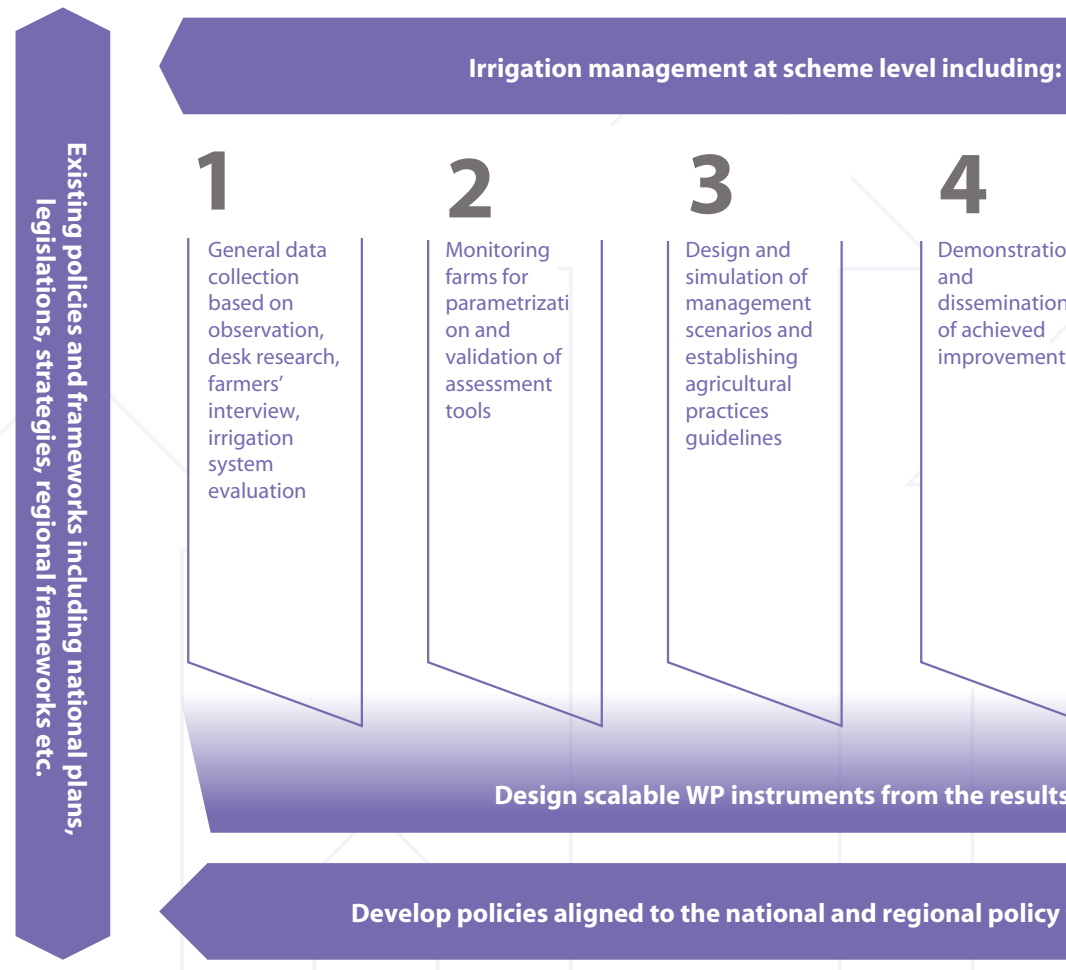

Irrigation management at scheme level including:

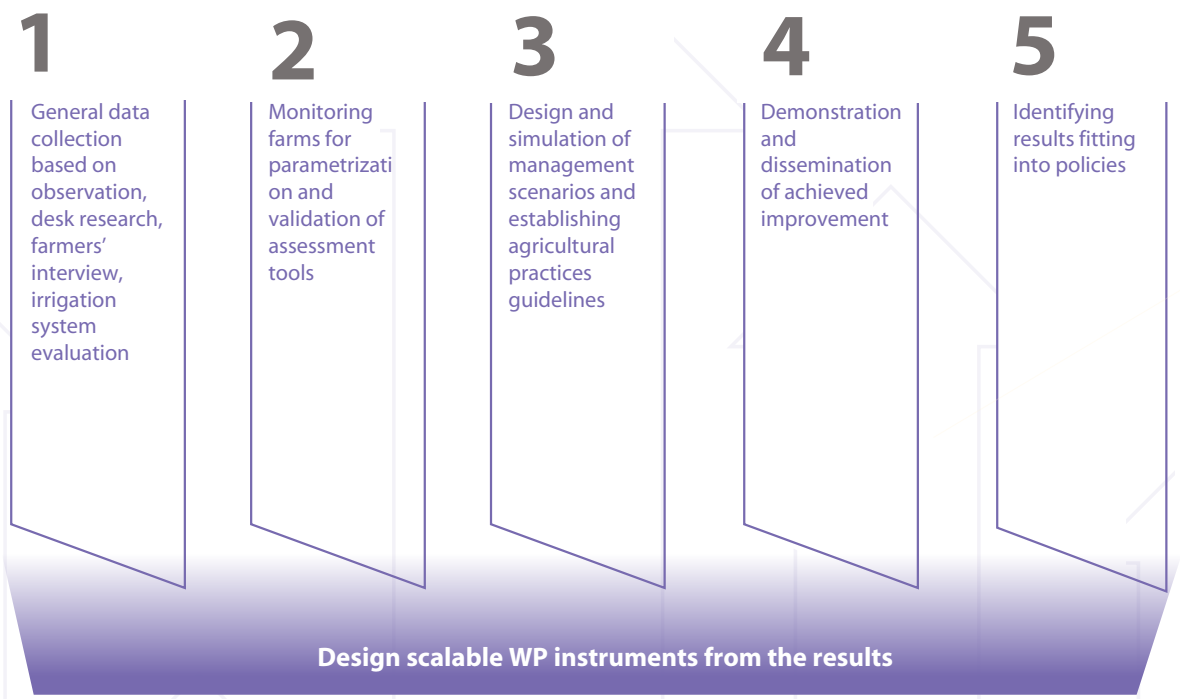

Develop policies aligned to the national and regional policy frameworks

to be collected. In data-scarce environment and in order to obtain a more detailed assessment beyond the general data collection at farm level, farmers' interviews were conducted to fill in the gap. The main objective of these interviews is to characterize current agricultural production levels and to describe on-farm irrigation and agronomic practices. The interviews were focused not only on water issues but on other production factors, in order to identify those that are possibly limiting production (pests, socio-economic issues, etc.), thus opening all avenues for improving WP. The inter-annual variability of management practices and production was also addressed and the locally implemented crisis-management strategies were mapped. The data acquisition was complemented with a number of irrigation system evaluations to assess the performance of the irrigation systems at farm level.

\section{Monitoring farms for parametrization/validation of assessment tools}

The number of assessment tools and methodologies of water productivity is ample. The current protocol applies FAO-developed AquaCrop model ${ }^{1}$. AquaCrop is a crop growth model enabling the yield responses to different conditions and management practices. Although the model is

1 More information is available about AquaCrop in the following website: http://www.fao.org/aquacrop 
already calibrated for the main herbaceous crops, some crop cultivars require some adjustment of parameters to adapt it to local conditions. In order to adjust the specific cultivar parameters, crops should be grown under different conditions in monitoring fields for the parametrization process: without any mineral nutrient limitation or water limitation (reference field); and with several combinations of nutrient limitations and/or water stress. The implementation of water-limited fields was conditioned by the particular irrigation management and environmental conditions. In the case of monitoring fields for the model validation process, farms with different characteristics and/or different on-farm management practices were selected in order to test the robustness of the model, and their own agronomic practices in these fields without following specific agronomic guidelines were observed. Locally adapted protocols included the following monitoring activities: soil sampling and analysis, climatic data collection, initial soil water content, crop development, green canopy cover evolution, applied irrigation water, and final biomass and yield.

\section{Design and simulation of management scenarios and establishment of agricultural practices guidelines}

For the completion of the diagnosis and benchmarking phase, data is to be carefully analysed and conclusions are to be drawn to define management scenarios. The potential and attainable yields were investigated under different management scenarios in order to reduce WP gaps. The possible causes of yield and WP gaps were structured around the three main working levels that directly affect yield and WP: irrigation water supply; irrigation management at farm level; and on-farm agricultural practices. The analysis of the data generated in the monitored fields, linked to the diagnostic activities performed in the previous phase, generated the relevant information needed to design local guidelines on good agricultural practices. The guidelines are comprehensive manuals on specific crop production including specific management practices on irrigation, land preparation, sowing and plant density, fertilization, weed management, and pest and disease control.

\section{Demonstration and dissemination of achieved improvement}

In order to demonstrate the attainable gains of introduced best agricultural practices, the treatment effect is to be measured. Through comparison between involved and control fields, the improvement can be demonstrated. Furthermore, improvement can be measured against the established baseline values of involved yields. The data obtained in the demonstration and control fields were compiled and analysed in order to define optimal farming practices. A communitybased approach was followed, where farmers are informed about the obtained gains of new agricultural practices. Established knowledge-transfer within and beyond the investigated scheme can help the gradual introduction of better performing agricultural practices. Designed agricultural practices provide benefits for farmers, while taking resource-efficient irrigation into account. In order to increase the flexibility of the applied approach, a widely-applicable protocol is provided (Figure 6). 
Figure 6: The flowchart designed for the development of WP theme

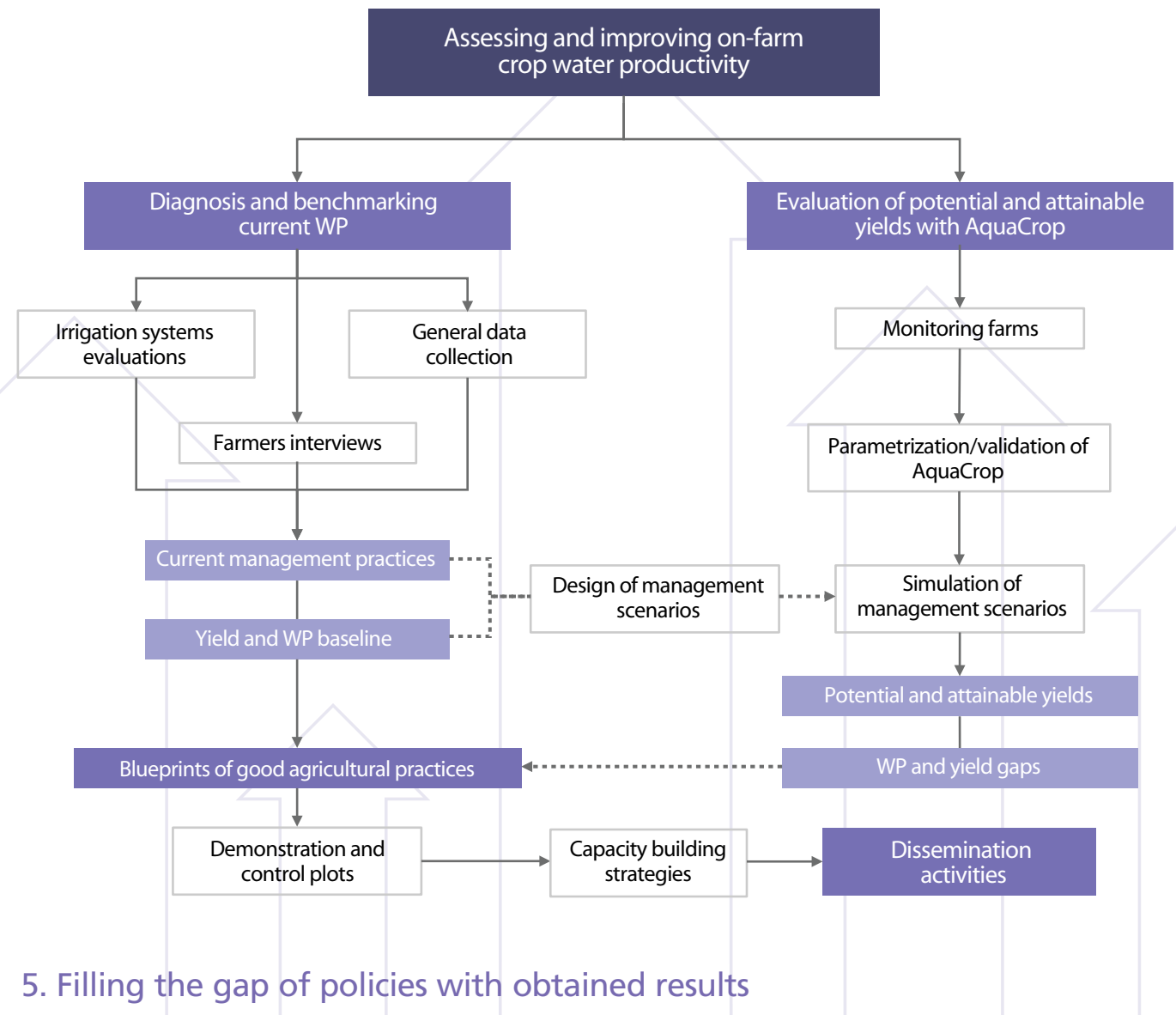

The scale-up process requires careful revision of obtained results and the identification of scalable lessons. In parallel to the implemented approach, policy mapping should be carried out. While involving a wide range of stakeholders from farmers to decision-makers, the willingness of adaptability is to be measured. This involved the surveying of farmers, discussions with local authorities and two regional workshops and conferences with the involvement of decision-makers ${ }^{2}$.

\section{WPls}

The successive steps of establishing management practices, rules and strategies lead to a final design of recommended instruments of WP. The instruments can be evaluated and then scaled-up to national and regional levels.

2 The thematic agenda and the discussion materials of the regional events can be found in the following links:

- August 2018, Saskatoon, Canada, International Conference and 69th IEC Meeting of the ICID: http://www.fao.org/agwa/newsevents/events/saskatoon2018/en/

- August 2017, Bari, Italy, Emerging Practices from Agricultural Water Management in Africa and the Near East - Thematic workshop: http://www.fao.org/agwa/newsevents/details/en/c/1039086/ 


\section{Policy guidelines for improving Water Productivity in Burkina Faso, Morocco and Uganda}

As first step, the guidelines provide an insight into the most relevant international, regional and national frameworks, strategies and policies in order to understand the possibilities of mainstreaming WP into the development pathways of the countries. It further underpins the linkages between international and national policies. Drawing from the national policies, it looks at the complementarity between evidence-based recommendations and existing frameworks.

\section{WP to meet SDGs, strategic objectives and the global water policy objectives}

The 2030 Agenda for Sustainable Development (SD) was adopted by country members of the United Nations in 2015. At the core of a consistent plan for sustainable development, 17 Sustainable Development Goals (SDGs) are designed to embrace all aspects of SD while recognizing that ending poverty and other deprivations can be achieved through improving health, education, reduced inequality and spur economic growth. Given that access to water is a key issue of SD, it appears directly and indirectly in many SDGs. Figure 7 gives an example on how water use efficiency and water productivity are mainstreamed into the different specific targets.

\section{Water related SDGs: Clean Water and Sanitation}

The project focused on improving WP, which can reduce water losses and optimize farming practices with all respect to the environment. This is in line with the target 6.4 of the SDGs that aims to substantially increase, by 2030 , WUE across all sectors and ensure sustainable withdrawals and supply of freshwater to address water scarcity and consistently reduce the number of people suffering from water scarcity. Two indicators have been developed to track the progress for this target: 6.4.1 "Change in water-use efficiency over time"; and 6.4.2 "Level of water stress: freshwater withdrawal as a proportion of available freshwater resources". WP can directly support the later indicator in order to improve the efficiency of a scarce resource. 
Figure 7: Water resource management mainstreamed into the specific SDGs (authors' own edition)

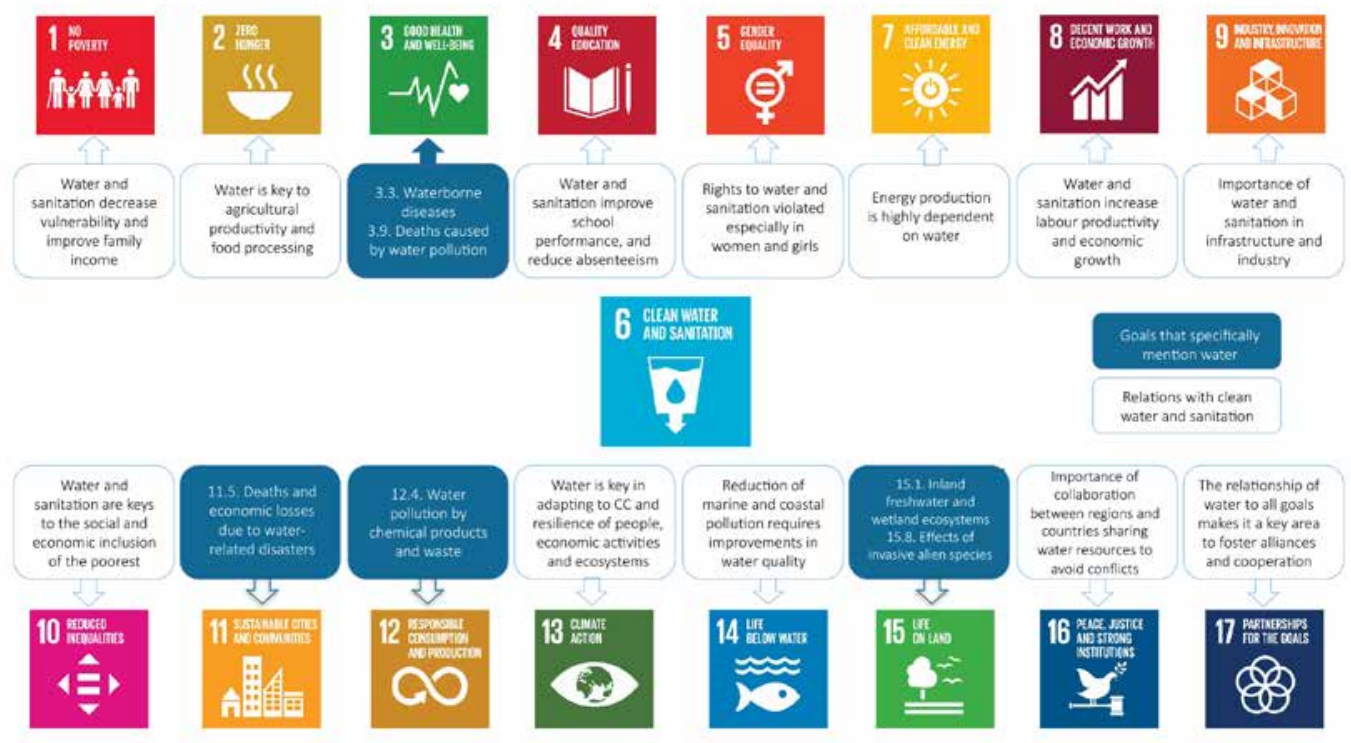

\section{Water related SDGs: Contribution to agriculture as a poverty reduction measure}

In African countries, a large percentage of the population relies on agriculture, and many live in extreme poverty. Access to production inputs are limited, and farmers are too poorly resourced to improve their farm management. However, agriculture provides a major contribution to economic growth. The majority of the farms, around 80 percent of the total number of producers, are smallholders, accounting for 175 million people directly employed in agriculture. The share of agriculture in GDP varies widely up to 52 percent. However, in most of the African countries, public expenditure in the agricultural sector is concentrated in on-farm investment in agricultural capital. The most common forms of support are the input subsidies and knowledge dissemination, while the majority of the countries does not invest sufficiently into agricultural infrastructure. This process targets short-term objectives, while long-term development goals are not emphasized enough. Increased focus on infrastructural development, researches, post-harvest technologies and marketing would certainly help to induce sustainable and long-term development.

\section{Water related SDGs: Contribution to socio-economic objectives as hunger eradication measure}

Globally, one out of nine people in the world today (815 million) are undernourished. The majority of them live in developing countries, where 12.9 percent of the population is undernourished. Poor nutrition causes nearly half ( 45 percent) of deaths in children under five -3.1 million children 
Improving water productivity can significantly reduce water stress in countries. In average years, $1000 \mathrm{~m} 3$ of water per capita can be considered as the minimum threshold to cover domestic and agricultural water needs in countries with irrigated agriculture. The following chart presents the pilot and some of their neighbouring countries. Two of the pilot countries have less total renewable water resources than the defined threshold. Improving productivity of water is, thus, crucial to address water stress and ensure the best use of water resources.

\section{Total renewable water resource per capita in 2017(1000 $\left.\mathrm{m}^{3} / \mathrm{capita} / \mathrm{year}\right)$}

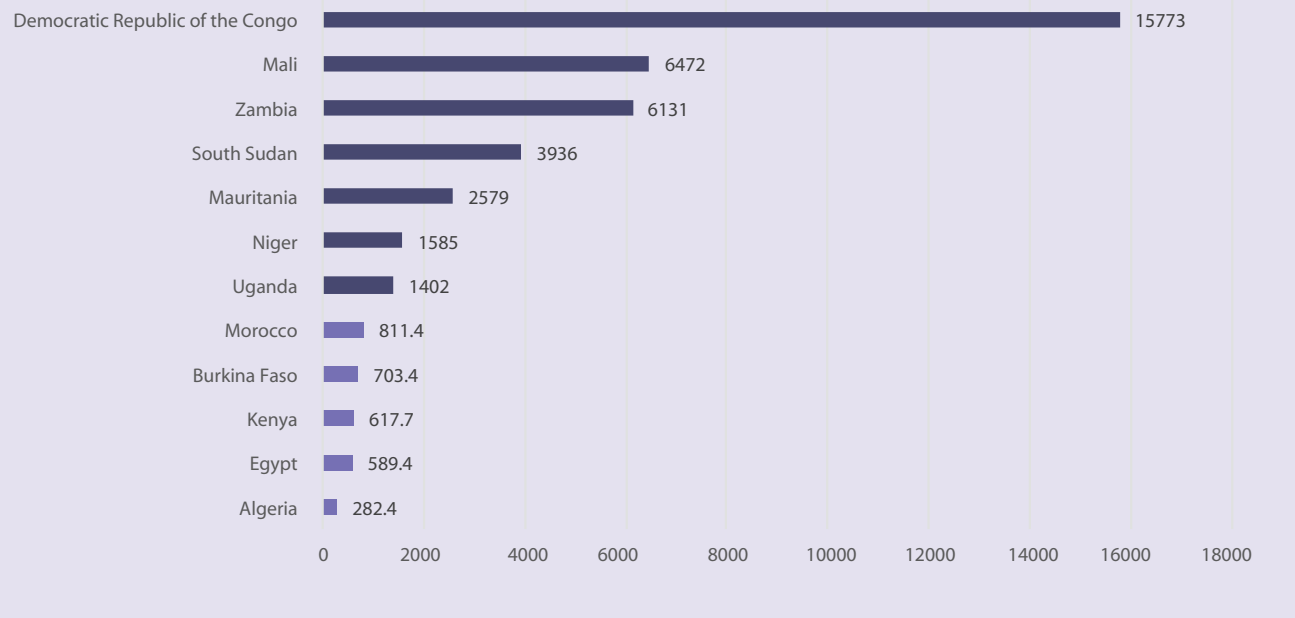

each year. One in four of the world's children suffers stunted growth. In developing countries, the proportion can rise to one in three. 66 million primary school-age children attend classes hungry across the developing world, with 23 million in Africa alone. On the other hand, agriculture is the single largest employer in the world, providing livelihoods for 40 percent of today's global

National development strategies define the main sectors, through which the countries envisage harmonized development. However, the substantial investment is needed to create enabling environment for highly productive agriculture. Analysis showed that on-farm investments exceed any other sources of investments. Decent on-farm investment is recognized in countries, where farmers succeeded to transition to commercial agriculture. Public spending and investment must be broadened to build-up the necessary frames for more productive agriculture. Furthermore, farmers must be supported to orient their investments to more sustainable and efficient agricultural production.

\begin{tabular}{llcccc}
\hline $\begin{array}{l}\text { Millions of US } \\
\text { dollars 2012 }\end{array}$ & $\begin{array}{l}\text { On-farm } \\
\text { investment in } \\
\text { agricultural } \\
\text { capital }\end{array}$ & $\begin{array}{l}\text { Government } \\
\text { Investment }\end{array}$ & $\begin{array}{l}\text { Public spending } \\
\text { on agricultural } \\
\text { R\&D }\end{array}$ & $\begin{array}{l}\text { Official } \\
\text { development } \\
\text { assistance }\end{array}$ & $\begin{array}{l}\text { Foreign } \\
\text { direct } \\
\text { investment }\end{array}$ \\
\hline Morocco & 1,287 & 206.7 & 70.6 & 33.3 & 2.8 \\
\hline Uganda & 582 & 33.3 & 25.5 & 56.3 & \\
\hline
\end{tabular}


Undernourishment rate in Burkina Faso and Uganda is above both the world and Africa average. Even though Uganda has enough water compared to Burkina Faso and Morocco, the percentage of undernourishment in three-year-average kept rising reaching over 40 percent.

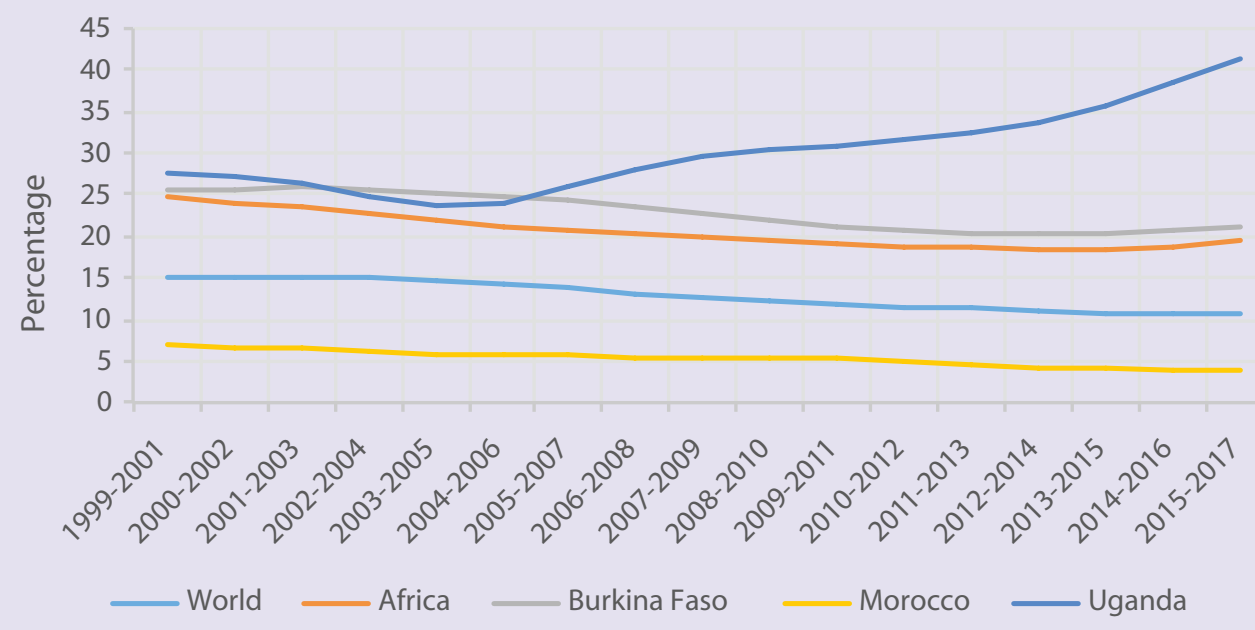

population. It is the largest source of income and jobs for poor rural households. 500 million small farms worldwide, in largest part still rainfed, provide up to 80 percent of food consumed in a significant part of the developing world. Improving WP contributes to sustainable use of resources, thus, to the overall sustainability of food production systems. WP is particularly important in countries hit by water scarcity, as well as in countries where projected population growth indicates rapidly increasing food demand in nearby future.

\section{Understanding the country focus: key features and national policies affecting water productivity}

The guidelines include a comprehensive review of existing water policies and frameworks in relation to water use and management. They provide an exemplary view on developing policy measures that can influence production and the numerator of WP function. To this end, the paramount importance of specific agronomic measures in maximizing WP, such as adequate mineral fertilization, optimal planting density and date, and crop protection, has been clearly illustrated. It is, therefore, necessary to explore both engineering and agronomic measures besides the management of irrigation water to achieve optimal WP in each situation.

\section{Burkina Faso}

Burkina Faso is paying attention to sustainable water use and is addressing country-wide water scarcity problem to increase food security. Currently, 20.7 percent of its population is 
undernourished. As Burkina Faso agriculture is subsistence agriculture, household food security is the primary objective of production. The contribution of the agricultural sector to the national GDP, between 2003 and 2008, reached up to 48.8 percent per year, but fell to 40.6 percent over the following five years. However, the country's agricultural share of total public spending approached, or even exceeded, the target set by regional relevant policies of 10 percent. The country's share averaged 20.9 percent per year during 1995-2003 and 10.0 percent per year during 2003-2008 and 2008-2014, with average yearly changes of $-19.0,7.0$, and -2.3 percent.

Likewise in terms of agricultural growth, Burkina Faso respected the target set by regional frameworks, as the sector grew by 6 percent on average between 1995 and 2003, by 7 percent between 2003 and 2008, and by 3.3 percent between 2008 and 2015.

Agriculture is mainly extensive throughout the country, with yields increasing from north to south, along with increases in rainfall and in natural soil fertility. The arable land reaches 6 million hectares, where traditional rainfed cereals (millet, sorghum, fonio, maize) represent more than 60 percent, and rice occupies about 98000 hectares. The other main crops are cotton, grown on about 586 000 hectares (the largest exported agricultural product), and rainfed peanuts, then vegetable and fruit crops, as well as sugarcane (DGPER, 2012). The irrigated areas in 2011 occupied approximately 54275 hectares, representing only 0.9 percent of the cultivated area, while currently the total area harvested is 7068370 ha, and the five most common crops take the 82 percent of the total cultivated land (Figure 8). The sector is dominated by small-scale farms and it employs the 90 percent of the workforce, with 73 percent of the population living in rural areas.

\section{Figure 8: Area harvested of the main crops in 2016, Burkina Faso}

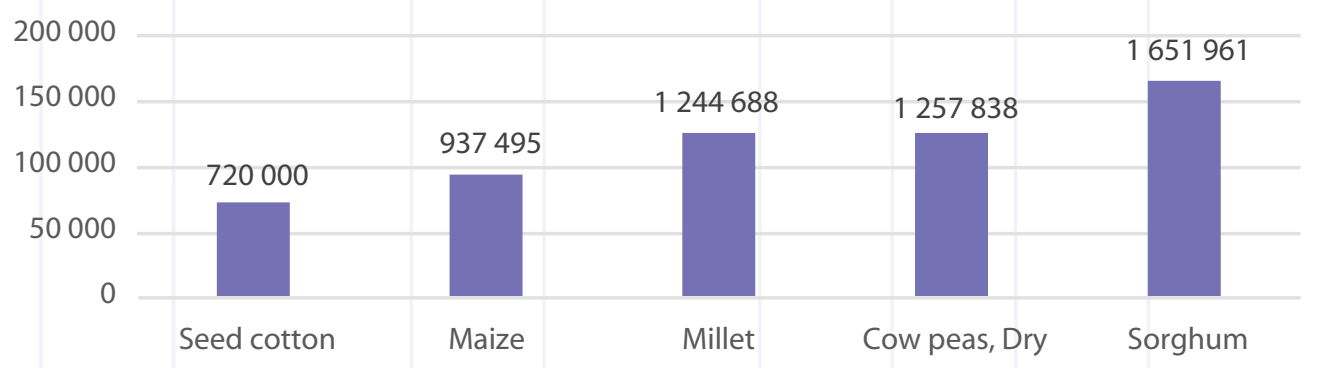

Source: FAOSTAT, 2019

Cash crops are an important source of income for farm households and contribute to a better management of cereal production (compensatory purchases). Irrigation development has been growing in recent years and contributes to food self-sufficiency and poverty reduction, especially in rural areas. Therefore, the tendency is to increase the lowland areas for the production of cereals (maize and rice), while the production of vegetables is an activity that generates income and essentially aims at increasing the purchasing power of producers. Despite a sustained growth rate 
of agricultural production in recent years (Figure 9), yields of main crops are only about 40 percent of potential yields (PNSR II, 2018).

Figure 9: Evolution of the yields of the main crops between 1961 and 2018

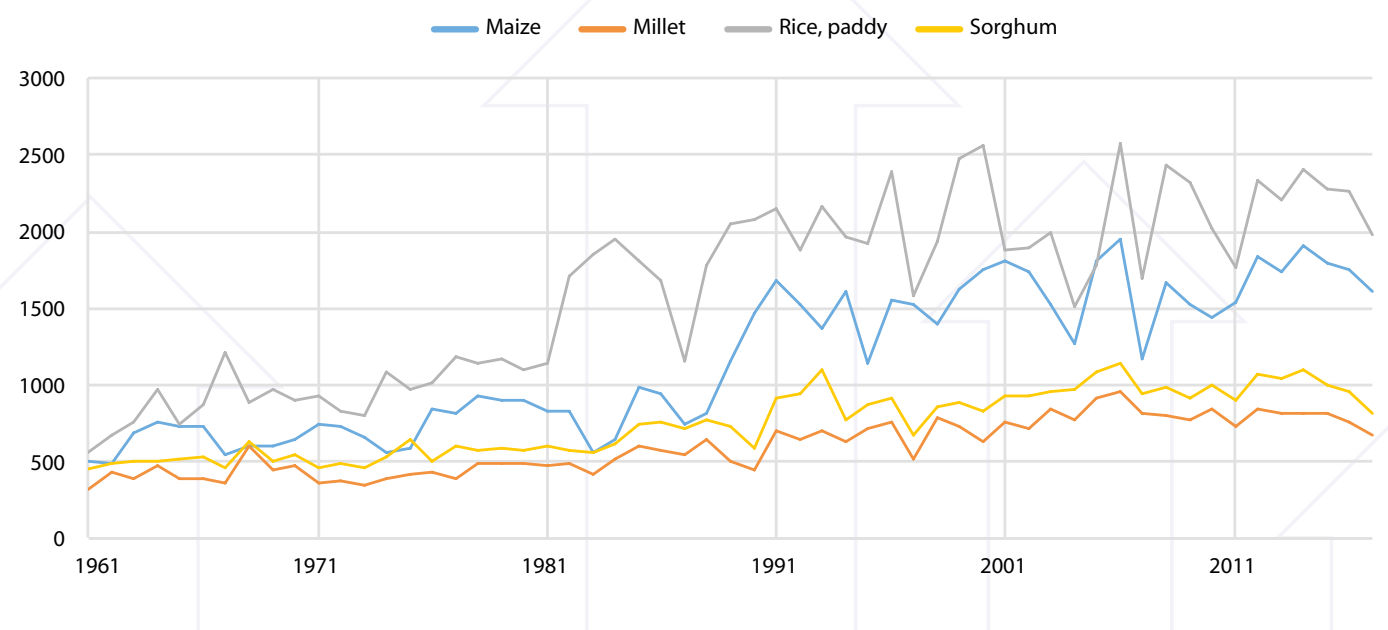

Source: FAOSTAT, 2019

The 2007-2008 food crisis forced the government to introduce subsidies for agricultural production, essentially through the provision of improved seeds and cost subsidies on fertilizers. Furthermore, the food crisis required trade restrictions. From 2008, the government banned cereal exports for 6 months to stabilize the domestic supply and avoid acute famine. Still, food insecurity and malnutrition rates are extremely high.

Figure 10: Tendency of area harvested of millet and sorghum compared to the number of undernourished people

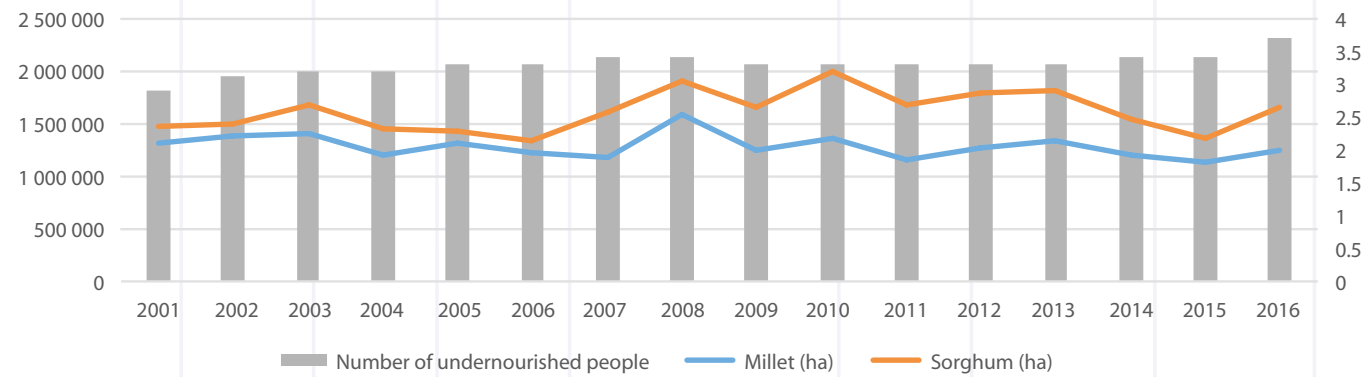

Source: FAOSTAT

Despite the threatening food insecurity, Burkina Faso is one of the country that achieved the Comprehensive Africa Agriculture Development Programme (CAADP) target to allocate at least 
10 percent of national budget for agriculture. As a result of the policy intervention, the public expenditure for irrigation infrastructure doubled between 2009 and 2010 (from 14 million to 29 million USD) and both sorghum and millet areas have expanded significantly, as compared to 1960s standard figures.

\section{Regional frameworks}

Classified as a low-income country with more favourable conditions (LI-2), Burkina Faso is a member of both the Economic Community of West African States (ECOWAS/Communauté Economique Des Etats de I'Afrique de I'Ouest - CEDEAO in French) and the Community of Sahel Saharan States (CEN-SAD). At regional policy level, ECOWAS adopted in 2005 a regional agricultural policy, la Politique Agricole Commune de la CEDEAO (ECOWAP), a regional translation of the Comprehensive Africa Agriculture Development Programme (CAADP/ Programme Détaillé de Developpement de I'Agriculture Africaine - PDDAA, in French) of NEPAD (New Partnership for Africa's Development). CAADP was originally endorsed by African leaders at the summit meeting of the African Union held in 2003 in Maputo. In order to advance from planning to effective implementations for long-term results, leaders and policy makers thus convened in June 2014 to sign the "Malabo Declaration on Accelerated Agricultural Growth and Transformation for Shared Prosperity and Improved Livelihoods", which nowadays remains the highest policy tool of reference. ECOWAP is the relevant framework for the region's interventions in agricultural development. Its goal is to build a successful regional market based on family farms and the promotion of agricultural enterprises through the involvement of the private sector. At outcome level, the regional policy specifically aims to: (i) sustainably respond to the nutritional needs of the population; (ii) enhance the economic and social development; and (iii) reduce poverty in member states.

Among the most outstanding actions carried out by ECOWAS are: (i) a regional emergency food reserve project; (ii) a pilot project under the G20 for the regional implementation of emergency humanitarian food reserves in West Africa, with the establishment of regional stocks, physically and financially; and (iii) the Zero Hunger project launched in 2014, which incorporates the Zero Hunger Initiative to eradicate hunger and malnutrition in the region by 2025 .

\section{National policy environment}

At national level, ECOWAP coordinates and is implemented through the National Agricultural Investment Plans (NAIP / Programme National d'Investissements Agricoles - PNIA in French), restarted in 2010 as Programme National du Secteur Rural (PNSR), the governmental unified planning and management tool for the rural sector. It translates the priorities indicated in the national strategy for rural development into specific programmes aligned to CAADP objectives. At regional level, a Regional Agricultural Investment Plan (RAIP / Programme régional d'investissements agricoles - PRIA in French) has also been developed to gather regional priorities and combine investments and policy reforms. It is structured around three objectives: 
- promotion of strategic products for food sovereignty (rice, maize, cassava, livestock and animal products, fish products);

- promotion of a general environment conducive to agricultural development; and

- improvement of access to food for vulnerable populations.

For their part, NAIPs reflect the priorities of national stakeholders and focus on productive investments in the wider agricultural sector (crop production, livestock, fisheries, forestry).

Based on sector development policies at national level, the strategic guidelines for rural sector are the vision of Burkina Faso for 2025, defined at the end of the Prospective Burkina 2025 national survey and the National Spatial Planning Scheme (SNAT). The Strategic Framework to Combat Poverty (CSLP), implemented from 2000 to 2010, was the national reference framework for action.

In the framework of the CAADP COMPACT signed in July 2010, Burkina Faso also developed a number of dedicated national policy instruments and strategic policies. As for the former, la Stratégie de croissance accélérée et de développement durable (SCADD), focuses on: (i) the improvement of agropastoral infrastructures; (ii) the promotion of agro-forestry-pastoral and fishery processing units; (iii) the modernization of agriculture and husbandry; and (iv) enhanced contribution of the sector to the environment, and in particular of the family households. The Stratégie de Développement Rural (SDR), on the other side, is a comprehensive national policy framework which aims at: (i) strengthening food security; (ii) increasing income of rural population; (iii) ensuring a sustainable management of natural resources; and (iv) empowering rural population as development agents.

The main strategies and policies of the agriculture, water and fisheries sub-sector are included in the National Water Policy (PNE) and the National Food Security Strategy (SNSA). To ensure greater coherence among the different policies and strategies of the rural sector, the National Programme for the Rural Sector (PNSR) began in 2010 and covered the period 2011-2015. The second National Programme for the Rural Sector (PNSR II) in Burkina Faso is the operational framework of the SDR (SDR for 2025) and the rural development component of the National Economic and Social Development Plan (PNDES) for the period 2016-2020. In addition, the PNSR II is the main instrument for the implementation of the SDGs related to the rural sector.

The overall objective of the PNSR II is to guarantee food and nutritional security through the sustainable development of a productive, resilient and more market-oriented agricultural, fisheries and wildlife sector. It is structured in 20 sub-programmes grouped around six priority investment areas:

1. Sustainable land management and adaptation to climate change.

2. Improvement of water management.

3. Sustainable development of agricultural holdings.

4. Enhancement of agricultural supply chain and promotion of markets. 
5. Prevention and management of food crises and related disasters.

6. Strengthening of institutions.

These six areas are well aligned with CAADP, being the result of a participatory decision agreed among development and technical ministries, research institutes, farmers' organizations, representatives of the civil society and the private sector. In the Programme, cost of the single programmes were indicated accordingly for each area.

Table 2: Individual cost of the PNSR II priority investment areas

\begin{tabular}{ll}
\hline Investment area & Costs (FCFA) \\
\hline Sustainable land management and adaptation to climate change & - \\
\hline Improvement of water management & 354.9 \\
\hline Sustainable development of agricultural holdings & 191 \\
\hline Enhancement of agricultural supply chain and promotion of markets & 70.3 \\
\hline Prevention and management of food crises and related disasters & 403.9 \\
\hline Strengthening of institutions & 43.4 \\
\hline
\end{tabular}

The indicated 20 sub-programmes, composed of actions, are the result of a distribution of the missions of the ministries in charge of the sector. To achieve the results of these sub-programmes, strategic reforms and structural investments are applied.

Among the six axes of the PNSR II, axis 1 focuses on food and nutritional security and resilience of vulnerable populations. It gathers five sub-programmes, namely: (i) Sustainable development of agricultural production; (ii) Prevention and management of food and nutritional crises; (iii) Hydroagricultural development and irrigation; (iv) Animal health and veterinary public health; and (v) Development of fishery and aquaculture production.

The first sub-programme is especially concerned with improving food security and food sovereignty, whose components are the sustainable development of agricultural products and their diversification. The aim of this sub-programme is to raise the level of agricultural production by improving access to agricultural inputs and equipment, better plant protection through the safe management of pesticides and the provision of adequate advisory support. At the same time, the third sub-programme aims to ensure and secure the availability of surface and groundwater for the sustainable development of agricultural production, given that irrigated production accounts for only 15 percent of total production in 2015 (PNSR II, 2018). The sub-programme should help to minimize the impact of climate hazards by increasing production through structural investments in the development of irrigation schemes, lowlands and innovative irrigation technologies. In relation to the latter, Action 4 focuses on ensuring efficient management and increasing the water productivity through the use of appropriate techniques and equipment for the development 
improvement, i.e. promoting the use of appropriate equipment and the development of supplementary irrigation and drip irrigation.

\section{Summary status: Burkina Faso}

The efforts carried out in developing agricultural policies have been considerable, at the regional and national levels, including application of guidelines of the SDGs of the 2030 Agenda. In recent years, the rate of economic and agricultural growth has continued to increase, despite the instability experienced by the region. The economy is heavily reliant on agriculture, since it employs more than 85 percent of the active population. However, agriculture is basically subsistence farming, with scarcity of resources/inputs and with actual crop yields very far from their potential.

The PNSR II (2016-2020) essentially proclaims the increase in agricultural productivity as a key issue to ensure food security through sustainable development. Several actions are established to achieve this goal in terms of improved access to inputs, improved plant protection, adequate advisory support, and improved irrigation water management.

To meet these objectives, applied practical tools were adapted for the improvement of WP throughout the project.

\section{Morocco}

The agricultural sector is the main axis of the Moroccan socio-economy, with an average contribution to GDP of 13 percent in the last decade (MAPMDREF, 2019), and an approximately 40 percent of the active population that depends on it, reaching almost 75 percent in rural areas. Most commonly, farm typology is dual although intermediate categories are observed. Small family farms with less than 5 hectares dominate the agricultural landscape, with more than 70 percent of the total Moroccan farms covering less than a third of the Utilized Agricultural Area (UAA). The fragmentation of properties and the lack of training make it difficult to practice high-performance agriculture, as well as to introduce advanced technologies in water and land management, and to provide technical support to farmers. The livestock sector is also a considerable component of the national agricultural economy and grasslands play a key role in the maintenance of the ecological balance, in addition to their socio-economic importance.

Cereals occupy the most consistent part of the UAA (59 percent), followed by fruit trees, argan trees, legumes and vegetables (Figure 11). However, they only accounted for less than 11 percent of the value of agricultural imports in 2018 (MAPMDREF, 2019). Cereals, indeed, are mainly grown in rainfed areas of the Atlantic plains, therefore, their production is influenced by climatic variability and thus to periodic droughts which cause significant fluctuations in productivity (Figure 12). On the contrary, early season vegetables, particularly tomatoes, are the backbone of Moroccan exports to the EU. 
Figure 11: Crop distribution in percentage of UAA in Morocco

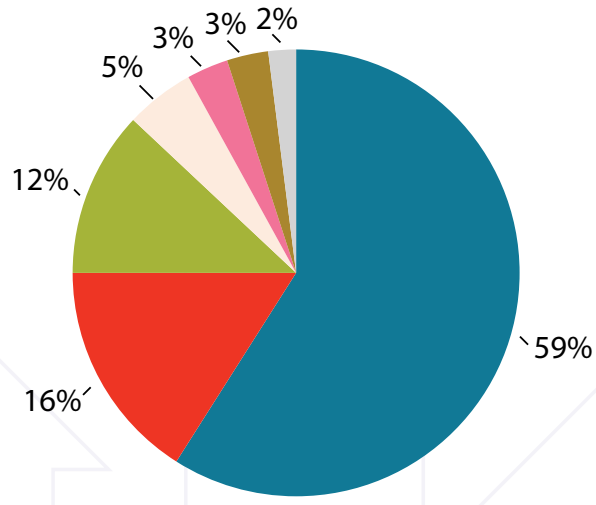

- Cereals

- Fruit tree plantations

Fallow

Fodder crops

Legumes

Vegetable crops

Others

Source: MAPMDREF, 2019

Figure 12: Evolution of the yields of the main cereals in Morocco for 1961-2017

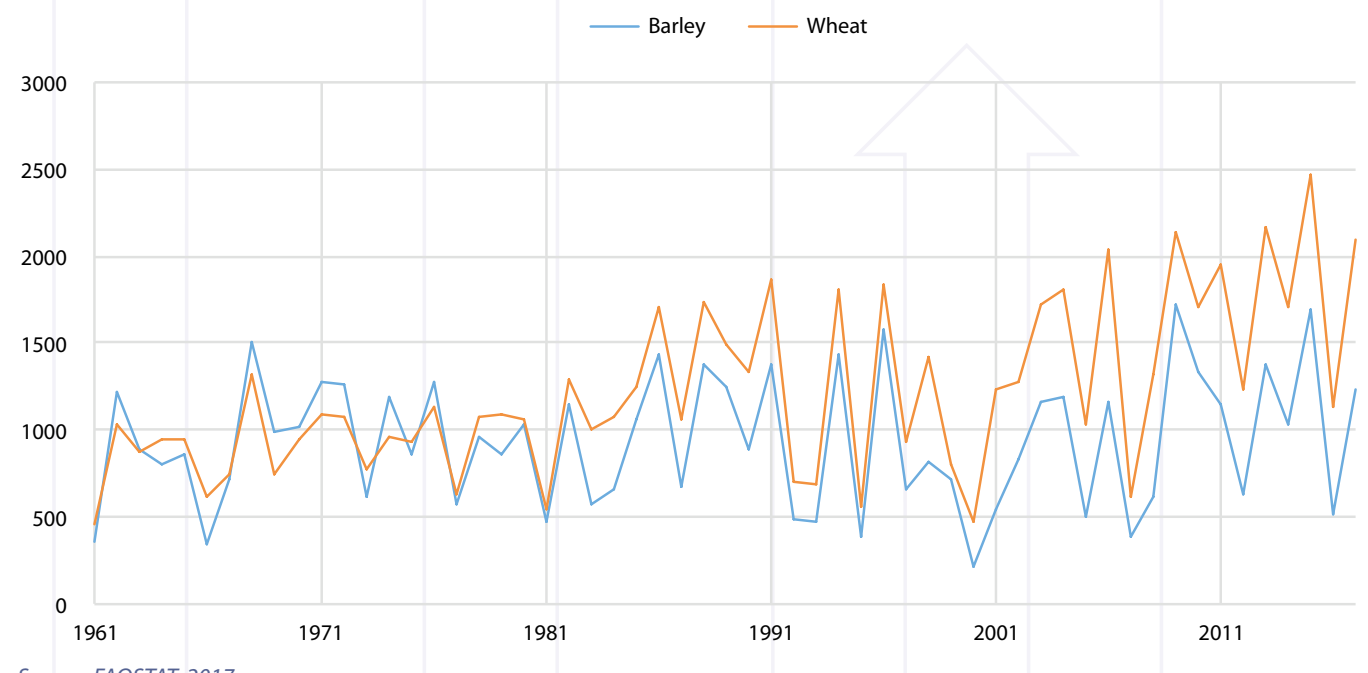

Source: FAOSTAT, 2017

Agriculture in Morocco has always been a strategic sector for the socio-economic development of the country. The National Agricultural Investment Plan is outlined in the "Green Morocco Plan" (Plan Maroc Vert, PMV, in French), whose broad objective is the modernization of agriculture through investment projects aimed at improving the efficiency of the sector. While the long-term goal of the PMV is the development of a high-performing agriculture, adapted to market rules, the challenges are represented by the economic development of the country, the reduction of poverty and the maintenance of a large rural population. The Plan's approach, geared towards the fight against poverty, aims at increasing the agricultural income of most vulnerable farmers and is developed through two main pillars: 
- Added value modern agriculture, targeting 400000 farmers and expecting to generate 150 billion Dirhams of investments through 900 project;

- Solidarity farming for small-scale agriculture, addressing $600000-800000$ farmers and up to 2 million of rural people, with foreseen investments for around 15 billion Dirhams.

In support of the Plan, significant public financial means have been mobilized over the years. The Plan is built on two pillars, reflecting the dual nature of Moroccan agriculture. The first one focuses on the development of large economic centres at the core of a productive agriculture with high added value, mainly oriented to export, with strong private investments complemented by public aid, in order to provide involved farmers with technical advice, credits, inputs and, also, to promote investments in the processing of agricultural products. The second pillar seeks to develop, in a spirit of solidarity, a small agriculture more oriented towards the internal market and capable of providing rural populations with better incomes, by concentrating certain actions in the most disadvantaged regions (mountains, Saharan areas), and taking into account the sustainability of natural resources. The Plan draws on local approaches to the territory and the use of geographical indications, in order to better value local productions. The PMV helped increasing agricultural investment, both private and public. The fruit, citrus, cereals, horticulture and olive sectors have, thus, made remarkable progress, both in terms of quantities produced and added value of production. At the same time, work on rural development, local products, and geographical indications, as well as the emergence of numerous cooperatives, many directly organized by women, have been important factors in enhancing the development of rural areas.

Irrigated agriculture in Morocco, although it occupies only 15 percent of the cultivated area, contributes about 45 percent on average of the agricultural value added and represents 75 percent of agricultural exports (MAPMDREF, 2019). This contribution is greater during drought years, when the production of rainfed areas is severely affected. The proposed strategy is to strengthen the regulatory framework to promote productive uses of irrigation and more efficient water service by the Regional Organization of Agricultural Development (ORMVA). This implies better cost recovery, better maintenance and a greater role for public-private partnerships in the management of existing schemes and the development of new ones. On the other hand, the National Programme for Saving Water in Irrigation (PNEEI), which is included in the PMV, aspires to making agriculture a pillar of the growth of the national economy. The PNEEI promotes more productive water use by introducing more efficient irrigation technologies (mainly drip irrigation) on 550000 hectares of irrigated land in Morocco. The incentive system covers the full cost of the drip installation for farms below 5 hectares, and 80 percent of the costs for farms larger than 5 hectares. As a result, the area under localized irrigation areas has been growing steadily for a decade since 2008 with the launch of the PNNEI.

From a regional perspective, it should be noted that innovative experiences have been implemented in Morocco that could be replicated both elsewhere in the country and in other African countries with similar environmental and socioeconomic contexts. Furthermore, some cooperation initiatives 
were launched by Morocco at COP 22 (in Marrakech in 2016), such as the initiative for the Adaptation of African Agriculture (AAA), which intends to reduce the vulnerability of the African continent and its agriculture to climate change.

\section{Summary status: Morocco}

Over the last decade, the agricultural sector has gained prominence in the economy and employment in Morocco. The sector is based on two pillars: smallholder farms, rainfed cereals, pastures for livestock; and large farmer-investors in fruit and vegetable crops, which demand more technical agricultural management. The PMV tries to respond to both realities, with considerable success since its launch in 2008 , and could, thus, serve as a guide for neighbouring countries. With regard to the improvement of irrigation management, the PNNEl has encouraged the conversion from surface irrigation to localized irrigation, thus, increasing productivity while reducing water losses.

Despite the reduced losses by localized irrigation method, commercialization of agriculture leads to increased water consumption. Thus, the further expansion of irrigated agriculture to continue boosting the agricultural sector in Morocco is threatened by increasing water scarcity. Irrigation subsidies help encourage greater use of groundwater, which leads to cases of potential overexploitation. Moreover, as water table drops, pumping costs for individual farmers and public groundwater supply schemes rise accordingly. Regulation of groundwater use has become essential, especially in areas with water shortage, in addition to the overall better alignment of agricultural development, water conservation, and environmental objectives.

The applied practical tools and measures proposed to improve WP in this project took all these considerations into account, aiming at promoting the sustainable use of irrigation water.

\section{Uganda}

Located in the Eastern Africa region, Uganda is a member of the Common Market for Eastern and Southern Africa (COMESA), the Intergovernmental Authority on Development (IGAD), and the Eastern Africa Community (EAC). The country is classified as low-income with more favourable agricultural conditions (LI-2) and its GDP growth averaged 6.0 percent per year between 2008 and 2015, while per capita GDP growth reached around 2.2 percent/year in the same period.

As in the case of most developing countries, agriculture remains the most important sector in Uganda's economy in terms of food and nutrition security, employment, exports, etc., and currently contributes 24 percent of GDP and 40 percent to export earnings. The sector employs between 65 and 70 percent of active population, out of which 71 percent are women, and 68 percent are youth, mostly living in the rural areas where about 80 percent of total agricultural output and marketed agricultural produce come from subsistence farming (UBOS, 2018). In terms of public investments, Uganda agricultural share of total public spending has been on constant rise since 1995, up to 4.3 percent/year during the 2003-2014 period. 
Uganda is regarded as a food basket in the Eastern African region as it has the potential to produce sufficient food to meet its own consumption needs and a surplus to export to other countries. For the most part, grown staple crops are grouped into cereals, roots and tubers, plantains and pulses. The most cultivated cash crop is coffee, followed by tea, cotton, cocoa and tobacco. In Uganda, agricultural productivity remained at the same level with aggregate increases in crop production being attributed to the expansion of cultivated land area. Some exceptions are noted, such as efforts leading to increased productivity in maize and rice over the last decade, thanks to the introduction of new improved varieties and crop management techniques (Figure 13).

Figure 13: Evolution of the yields of the main cereals in Uganda for 1961-2017

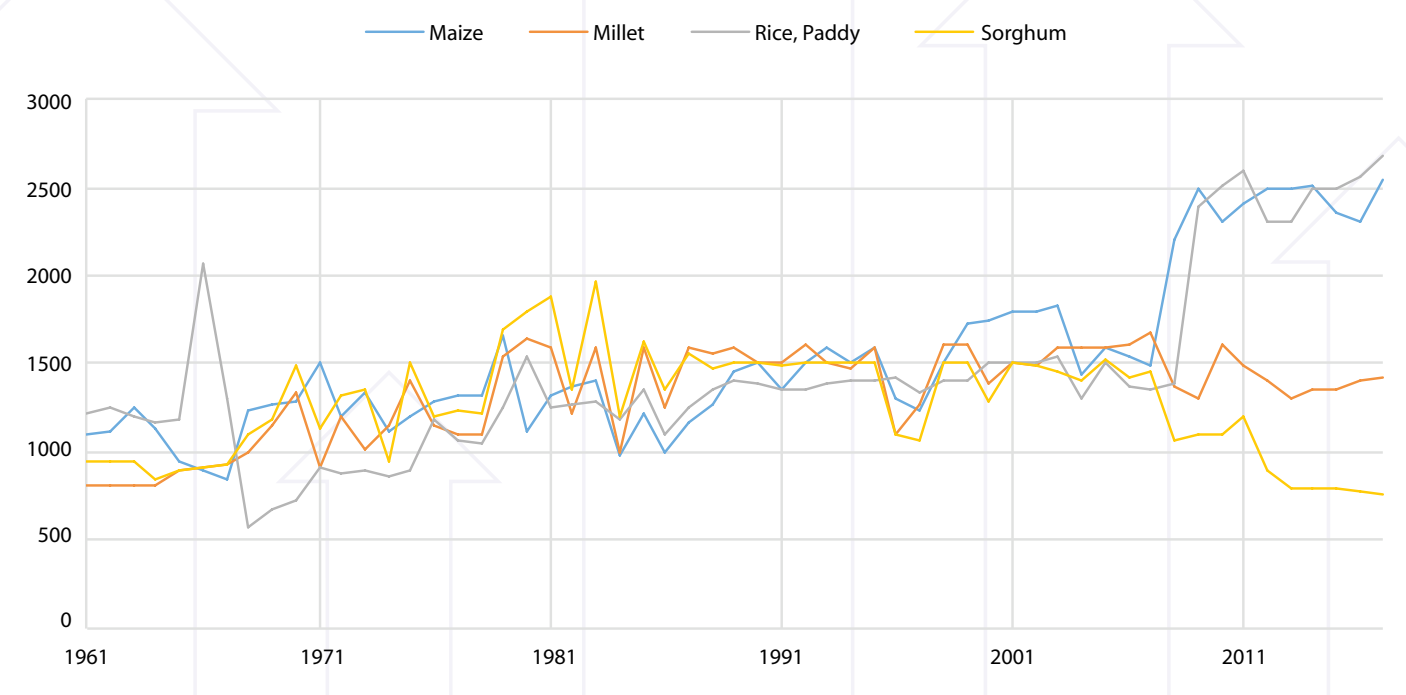

Source: FAOSTAT, 2017

The 2030 Agenda for Sustainable Development provides the global context for green growth, laid down in the Uganda Vision 2040,"A Transformed Ugandan Society from a Peasant to a Modern and Prosperous Country within 30 Years", promoted by the National Planning Authority and signed in 2013 by the country President. It develops through five-year National Development Plans, the current one being the 2015-2020 NDPII, "Strengthening Uganda's Competitiveness for Sustainable Wealth Creation, Employment and Inclusive Growth". The Plan also seeks to leverage the country's growth opportunities and honours development and partnership obligations at the national, regional and global levels e.g. EAC, COMESA, IGAD, Africa Agenda 2063, the Post 2015 Development Agenda, and UNFCCC (NDPII, 2015). For regional integration, formal mechanisms for trade within the region through EAC and COMESA have been developed, harmonizing all internal taxes with trade partners in the region. At national level, on the other side, the goal of the NDPII is to attain middle-income status by 2020 through strengthening the country's competitiveness for sustainable wealth creation, employment and inclusive growth. Among the four development objectives, Objective 1 should be highlighted: "Increase Sustainable Production, Productivity and Value Addition in Key Growth Opportunities". The NDPII rightly considers some aspects of 
the agricultural development value chain, such as agro-processing, infrastructure, storage and marketing as being beyond the mandate of the agricultural sector and therefore to be addressed by the responsible sectors.

Uganda signed in 2010 the CAADP Compact, which represents the regional framework for national agricultural policy. The Agriculture Sector Strategic Plan (ASSP) for the period 2015/16 to 2019/20 operationalises the National Agriculture Policy (NAP), and takes into account the development priorities in the NDPII. For ASSP, the overall goal of the agricultural sector is: "To achieve an average annual growth rate of 6 percent over the next 5 years". During the implementation period, activities focused on four priority areas: (i) increasing production and productivity; (ii) addressing challenges in the selected thematic technical areas including critical farm inputs, mechanization and water for agricultural production; (iii) improving agricultural markets and value addition in the prioritized commodities; and (iv) institutional strengthening for agricultural development. Finally, the ASSP indicates the following key outcome targets to be achieved during the plan period:

- Increase productivity at farm level to at least 50 percent of the yields achieved at research stations for the 12 priority commodities.

- Transform subsistence farmers (growing for own consumption) into enterprise farmers (growing for consumption and responding to market needs) and transforming smallholder farmers into commercial farmers.

- Increase food security and food availability in all parts of the country.

- Increase agriculture exports to at least USD 4 billion per year.

- Reform and strengthen agricultural service institutions such as research, extension and regulatory bodies to make them effective and efficient.

\section{Summary status: Uganda}

Uganda faces development challenges such as need for further investments, increasing impacts of climate fluctuations or the hosting of a growing number of refugees, in an increasingly unstable region.

Since the 1990s, numerous national development policies have focused on achieving food and nutrition security and improving household income through the enhancement of sustainable agricultural productivity and adding value. The results obtained so far have been limited, and there has been intermittent functioning in the agencies and in mechanisms responsible for implementation, especially with regard to financing. The modernization of Uganda agriculture requires a change to increase the allocation of resources to enhance small-scale farming, agricultural research, training of farmers in new production methods, enhanced investment in this sector, and effective technology transfer.

The methodology proposed in the project for the improvement of WP in small farms aimed at addressing these issues and align them with the current agriculture policies. 
Through plans, such as ASSP, the challenge today is to transform agriculture from the predominantly rainfed, low input, and subsistence farming to resilient and market-oriented production.

\section{Water productivity interventions and alignment with coun- tries' agricultural policies}

Being water productivity one of its main component, the project provides support to facilitate its enhancement in the three African countries: Burkina Faso, Morocco and Uganada. These countries fall within different contexts and exemplify three sub-regions of the continent: Burkina Faso, as a Sahelian country at the heart of West Africa; Morocco, a country bordering the Atlantic and the Mediterranean in North Africa; and Uganda, a landlocked country in East Africa located on the Equator. This section presents the main findings and lessons learned in the pilot irrigation schemes selected, and how designed policy instruments can be included in current and future country policies.

\section{Burkina Faso: staple crop versus cash crops}

For a continental Sahelian country like Burkina Faso that does not have enough water resources, irrigation development must be in line with sustainability objectives. Sourou is one of the so-called food basket of Burkina Faso. The Government converted Sourou Valley to the production and distribution center of rice supply. Close to the Sahel, Sourou is threatened by the desertification, land degradation, decreasing rainfall, and eroding soil. Agriculture is the only economic sector in the region due to the lack of industrial activities and service sector.

The region is characterized by a dry subtropical climate, with the influence of the seasonal alternation of humid air from the monsoon coming from oceanic high pressure and dry air from the Sahelian latitudes. There are two marked different seasons: a rainy season (May to October) and a dry season (November to April), with an average annual rainfall of about $750 \mathrm{~mm}$. The potential irrigation development of Sourou Valley is about 24000 hectares, of which 6500 hectares have already been developed at 80 percent under surface irrigation. There are around 7000 smallholders with an average field size between 0.5 and 1 hectare. A development project with multiple objectives has been established since 1986 by the Sourou Valley Development Authority (AMVS), a public institution belonging to the Ministry of Agriculture and Hydraulic Development (MAAH).

The AMVS has adopted a development plan for the fulfilment of its objectives: (i) research, mobilization, establishment and management of financing; (ii) studies leading to the development and rational exploitation of lands located in the Sourou Valley; and (iii) establishment and control of the essential infrastructures for the exploitation of the lands and auxiliary equipment. Among the irrigation schemes managed by the AMVS, Ben Nafa Kacha irrigation scheme covers 275 hectares, cultivated by around 250 farmers, with 165 hectares devoted to growing paddy rice in monoculture, and 110 hectares devoted to maize and horticultural crops (onions, tomato, and 
pepper). The agronomic practices vary between farmers in terms of time of sowing/seed planting, applied agronomic technologies, applied inputs, time of harvesting. Table 3 represents the period of cropping seasons, and the targeted market.

Table 3: Main cropping seasons and targeted market in Ben Nafa Kacha

\begin{tabular}{llll}
\hline & Production period / harvesting & Market \\
\hline & $\begin{array}{l}\text { Dry season/ irrigation } \\
\text { campaign }\end{array}$ & $\begin{array}{l}\text { Humid season/ } \\
\text { rainfed }\end{array}$ & \\
\hline Rice & February - June & July - November & Consumption, domestic market \\
\hline Tomato & October - January & $\begin{array}{l}\text { Consumption, domestic market, } \\
\text { export market }\end{array}$ \\
\hline Onion & October - January & & $\begin{array}{l}\text { Consumption, domestic market, } \\
\text { export market }\end{array}$ \\
\hline Maize & & May - September & Consumption \\
\hline $\begin{array}{l}\text { Other (pepper, } \\
\text { aubergine, herbs etc.) }\end{array}$ & October - March & May - November & Consumption \\
\hline
\end{tabular}

Tomato, onion, maize and other cultures are cultivated in rotation, while rice is produced in monoculture both in the humid and in the dry season. Farmers are the tenants of the lands, and they are responsible to maintain the land and water resources. They are free to choose crops, but they receive water in dictated rotation. None of the farmers owns production equipment, such as machines or post-harvest technologies.

There is an important local market for onions, and a potential export trade market. The main drawback in horticultural crops is the lack of marketing channels and the instability in market prices (Figure 14). In addition, the Sourou Valley is located in an area with very poor transport routes hindering trade for cash crops. The scheme officially started up in 1997; the water pump initially driven by an internal combustion engine, was recently replaced by an electric pump. The Water User Association (WUA, OUEA in French) of Ben Nafa Kacha is responsible to operate and maintain the irrigation infrastructure within the scheme.

Table 4: Fluctuation of local onion market prices

\begin{tabular}{llll}
\hline & Off-season & Pre-harvesting period & Harvesting period \\
\hline Yield (t/ha) & 20 & 20 & 20 \\
\hline Farmers price (XOF/t) & 326923.1 & 246153.8 & 96153.8 \\
\hline Cost (XOF/ha) & 1444590.0 & 1444590.0 & 1444590.0 \\
\hline Income (XOF/ha) & 6538461.5 & 4923076.9 & 1923076.9 \\
\hline Profit (XOF/ha) & 5093871.5 & 3478486.9 & 478486.9 \\
\hline Profit (USD/ha) & 7640.81 & 5217.73 & 717.73 \\
\hline
\end{tabular}


Figure 14: Profitability of onion in Ben Nafa Kacha, 2018

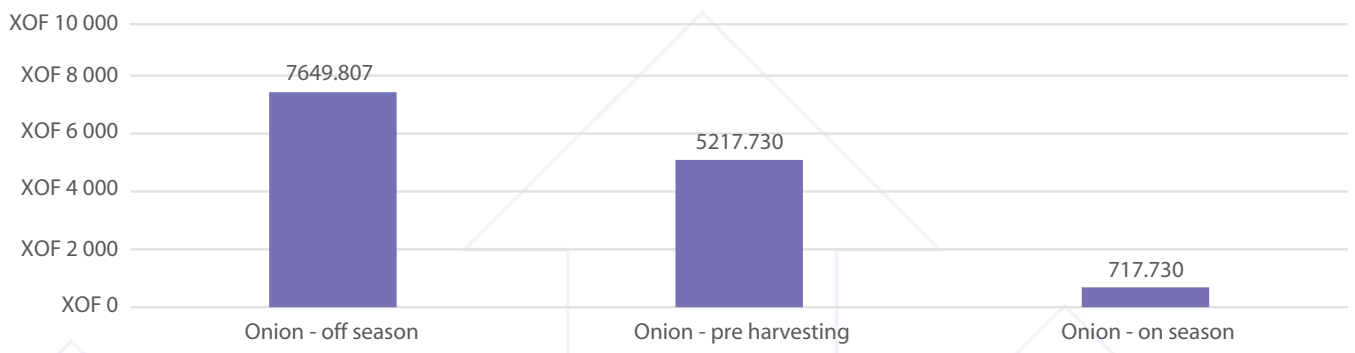

The major part of the production cost consists of seeds, fertilizer and water use; the three inputs share 37 percent of the total cost. The water fee collected by the cooperative is about 75000 XOF/ $\mathrm{ha} / \mathrm{campaign}$. Since half of the onion production is for self-consumption, the real-term profit of the farmers is half of the field value. The lowest price provides around 350 USD profit/ha for a year. The onion production suffers from market risks; farmers' profitability depends on the market access and timing of sales.

\section{Prevailing paddy rice}

Notwithstanding the rapidly growing interest, rice occupies only 2-3 percent of the total cultivated area in Burkina Faso. Until 2008, rice production was marginal, however, the policy intervention in 2008 had a major effect on rice production. The food crisis of 2008 required a prompt answer from the government to stabilize the market. The first response was the reduction of taxes on rice and milk, the distribution of seeds and fertilizer to farmers, and the provision of advisory system to farmers in large irrigation schemes. As represented in Figure 15, the area harvested has more than doubled after the intervention.

The annual consumption of rice per person is $50 \mathrm{~kg}$ in urban areas; meanwhile, the national average is about $10-15 \mathrm{~kg}$ per person. 60 percent of total rice supply comes from import, while the domestic production is from five large-scale irrigation schemes: the Sourou Valley, Bagré in the Centre-Est region, the Kou Valley and Banzon schemes in the Hauts-Bassins region, and the Douna and Karfiguela rice-growing schemes in the Cascades region.

Rice is a diversification crop with limited expansion only to irrigation schemes or lowland ecosystems, due to its high water requirement and its management needs. However, its area is expanding thanks to the irrigation promotion policy and donor support (support for growth poles such as Sourou and Bagré). The strong growth in rice consumption in urban areas of West Africa has led to rice imports increase while the government is trying to promote rice production in order to meet this growing demand. In the country, a potential area of 500000 ha of lowland ecosystems is estimated, with less than 10 percent currently developed and more than 233500 ha of irrigable lands, of which less than 5 percent are currently developed. The subsidy policy 
Figure 15: Rice area expansion between 1960 and 2017

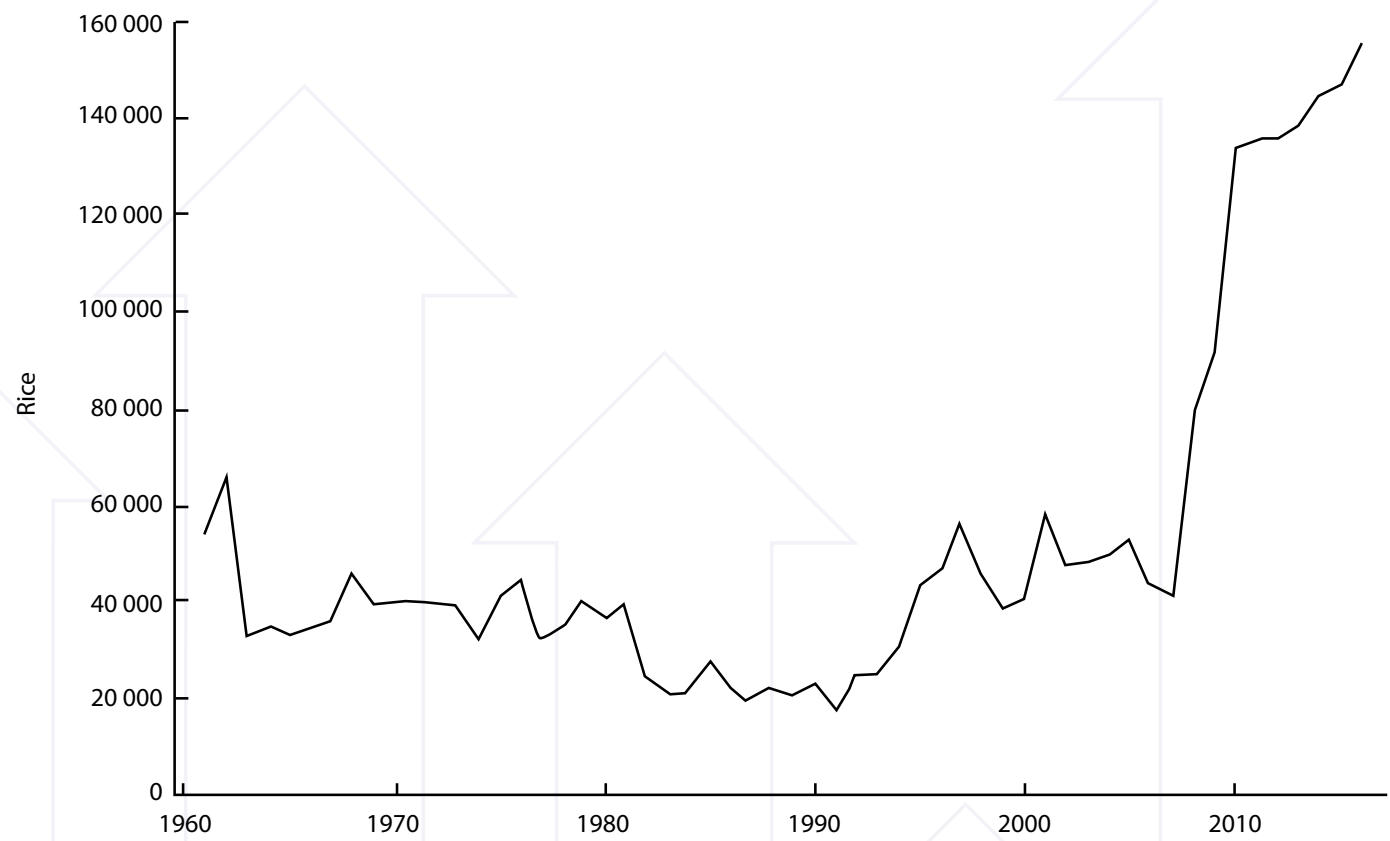

Source: FAOSTAT, 2017

represents a highly effective instrument to improve food security and to fight poverty, however, the amount of granted subsidies is not sufficient for producers, due to their large number. The difficulty in its implementation is due to the country's lack of financial resources and, thus, the need to constantly turn to foreign donors to finance projects in this sector. Several measures have been taken to implement changes, so far with little success: suspension of customs duties, setting up of a minimum price, introduction of a maximum price, installation of control stores and price control. Import rice became one of the most regulated staple commodities. Since 2012, the price kept stable at 350-400 XOF/kg, with the domestic rice production still 20 percent below the import price. The government introduced trigger price for domestic paddy rice based on consultation with farmers. The latest trigger price is set at $130 \mathrm{XOF} / \mathrm{kg}$ in 2012. Rice production in pumped irrigation schemes also faces high-energy costs, within the so-called water-energy-food nexus. National production that competes in open markets is sold with difficulty, despite the subsidy policy. Pumped irrigated rice cropping is not profitable enough if producers have to bear the total costs of O\&M (Figure 16).

Notwithstanding its importance, rice production is critical in terms of productivity and profitability. Fertilizers, organic manure and water use share 40 percent of the total production cost. In case of rice production, water use represents the highest cost in the total cost of production at 100 $000 \mathrm{XOF} / \mathrm{ha}$. Survey conducted in 2018 found that certified seeds and adequate fertilizer are not available to farmers, and recently, no organization in advisory function was provided to support them. Moreover, such conditions prevent farmers from reaching a medium-level yield and the production results in a negative cash flow. 
Table 5: Profitability of rice in Burkina Faso

\begin{tabular}{llll}
\hline & Low yield & Medium yield & High yield \\
\hline Yield (t/ha) & 4 & 5 & 6 \\
\hline Farmers price (XOF/t) & 150000.0 & 150000.0 & 150000.0 \\
\hline Cost (XOF/ha) & 617452.5 & 617452.5 & 617452.5 \\
\hline Income (XOF/ha) & 600000.0 & 750000.0 & 900000.0 \\
\hline Profit (XOF/ha) & -17452.5 & 132547.5 & 282547.5 \\
\hline Profit (USD/ha) & -26.18 & 198.82 & 423.82 \\
\hline
\end{tabular}

\section{Figure 16: Profitability of rice in Ben Nafa Kacha}

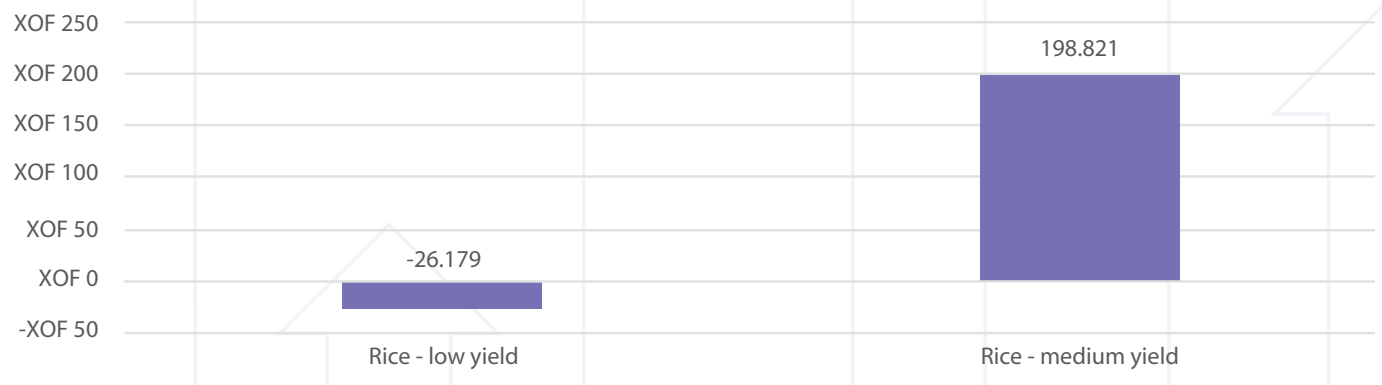

In Ben Nafa Kacha irrigation scheme, 60 percent of the area is devoted to paddy rice, which is grown twice a year, during rainy and dry seasons. The average yields achieved in the area are 4.5 t/ha, above the national average. Agronomic practices are generally acceptable, except for some inconveniences that require a decisive intervention such as the availability of potassium fertilizers, the suitability land levelling by mechanical means, or the use of appropriate plant protection measures when needed. Weeds can be controlled through a combination of appropriate cultural practices by mechanical, manual and chemical means, outlined under Integrated Pest Management (FAO, 2002; IRRI, 2019). However, farmers have currently no access to information. Furthermore, they are under pressure of continuous production to generate income but the continued cultivation of rice for several years in the same field exacerbates the weed problem. Effective regulation should be introduced to support farmers in self-rehabilitation of lands, such as set-aside practices.

Recommended WPIs: Increasing water productivity of rice remains a challenge. Paddy rice systems have the highest water requirement, while profitability of the crops are often marginal. However, rice is gaining importance in the list of staple crop in Burkina Faso, therefore, its role in household food security has paramount importance. Based on the identified constraining factors, the following instruments are recommended: 
- Unlocked information and database for paddy rice growers: centralized knowledge sharing for farmers to improve paddy rice production practices either at national or regional level. South-South or triangle cooperation holds the potential to transfer technology and knowledge.

- Improved farm economics through WP: profitability is one of the main constraints to the improvement of production technology, also due to the little market power of smallholders to negotiate on prices. Until farmers gain a more stable market situation, production costs should be addressed in order to enhance profitability. Improving water productivity certainly helps to optimize cost of water, thus, the overall cost structure of rice production.

- Special practices for paddy rice production: farmers are in the vicious circle of production pressure. The more they exploit natural resources such as water and soil, the more they are exposed to yield losses. Public subsidies could support farmers introducing set-aside practices to conserve natural resources and improve productivity in the same time.

\section{Limited availability of agricultural inputs}

The multiplication of quality seeds for staple crops has increased considerably in recent years, although the use of quality seeds by small producers who grow other crops than cotton remains limited. In the last decade, the Institute of Environment and Agricultural Research (INERA) and the Ministry of Agriculture have promoted the production of quality seeds of staple food crops, with maize and rice experiencing the greatest expansion. Despite this, basic seed production still does not meet the specifications of private seed producers, who, on their side, are expected to respond to national needs. Therefore, the supply of improved seeds does not comply with the national demand for staple crop production and cannot contribute enough to reduce imports. Thus, improving the production of quality seeds of staple crops is of paramount importance.

On the other hand, fertilizer suppliers estimate that at least 85 percent of the fertilizers imported to Burkina Faso and distributed to farmers was intended for cotton farmers before the introduction of the fertilizer subsidy programme in 2008. Since then, there has been a growing demand for subsidized fertilizers for other staple crops, yet, there was no clear trend for increasing fertilizer imports in recent years partly due to external factors affecting growers. The poor quality of roads, as well as high illicit taxes along commercial corridors, also contribute to the increase in fertilizer distribution costs. Subsidized fertilizers are often delivered late through the regional and provincial authorities of MAAH. In addition, it is important to note that the legislative and regulatory framework for the importation and distribution of inputs is quite precarious, and is dominated by cotton companies. Fertilizers' quality and labelling authenticity tests (ingredients in the claimed proportions) are also limited. The fertilizers' subsidy programme is estimated to have cost USD 7.7 million annually (2003 to 2011) without showing significant results (World Bank, 2013).

As the cost-benefit analysis in Ben Nafa Kacha shows (Figure 17), fertilizers' use has multiple effects on rice farm profitability. NPK, urea, manure and their transportation together share up to 28 percent of total cost. 
Figure 17: Rice cost composition in Ben Nafa Kacha

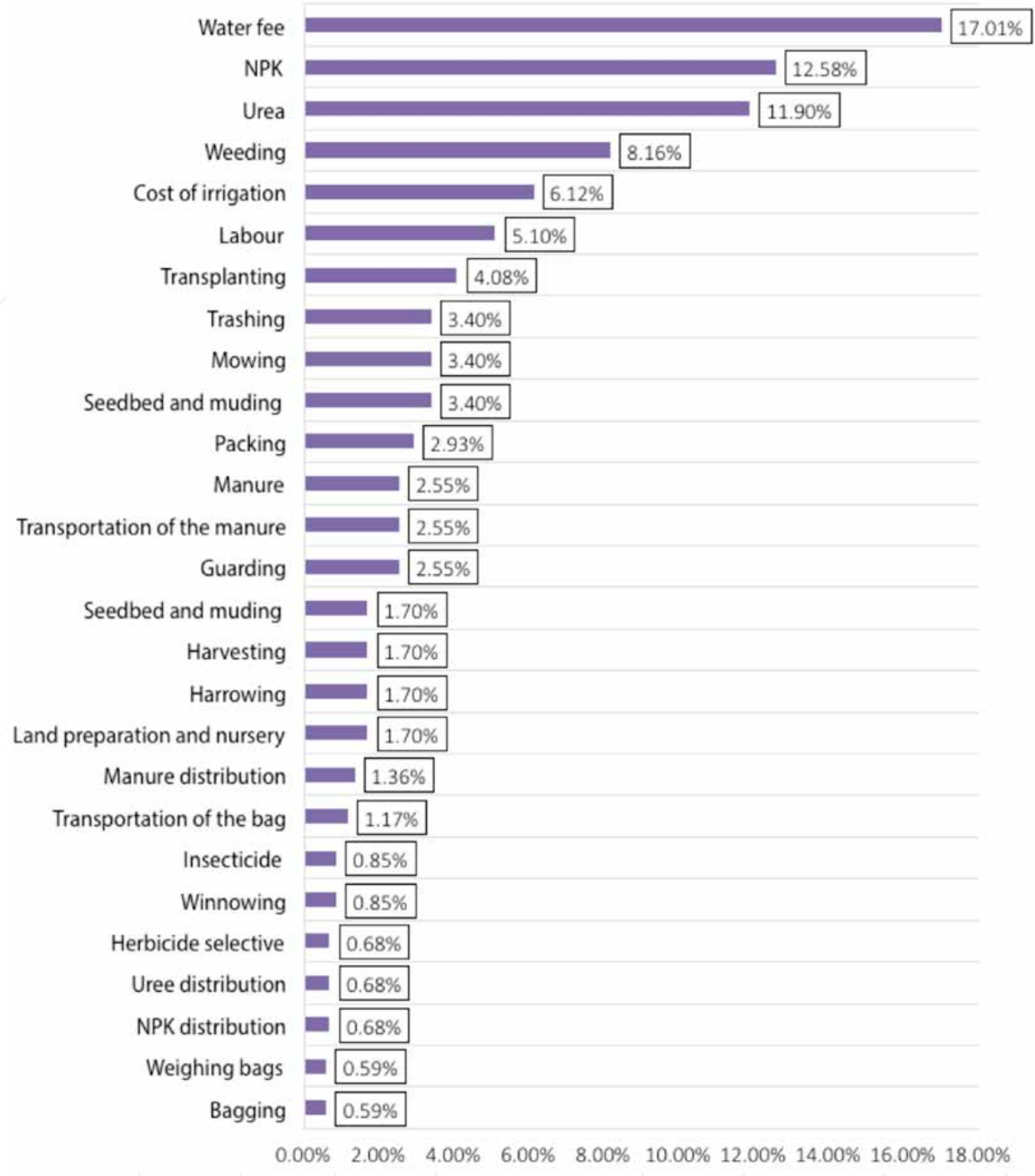

The PNSR II addresses these deficiencies in agro-inputs in the first sub-programme of axis 1, focused on the sustainable development of agricultural production. Specifically, under Action 1 "Promote producers' access to quality agricultural supplies and equipment", Action 2 "Plant protection and packaging of agricultural products", and Action 3 "Agricultural research and development, extension and advisory support". The implementation of this sub-programme is expected to increase cereal production to around 7.1 million tons by 2020, while the coverage of cereal crop needs should reach 140 percent. Within the PNDES, sub-programme 1 addresses the infrastructure 
improvement in its Strategic Objective 3.4: "Develop quality and resilient infrastructure to promote the structural transformation of the economy". The objective, among others, is to increase the proportion of asphalted roads to 42 percent in 2020, and the proportion of managed rural roads to 43 percent in 2020 .

It is, therefore, not surprising that problems in the availability of adequate agricultural inputs (seeds, fertilizers and phytosanitary products) of good quality is revealed in remote schemes. This is mainly due to the isolation of the area and the high costs of the products. Thus, the involvement of the public and private sectors to encourage farmers' accessibility to sufficient farm inputs is an important challenge and opportunity.

Recommended WPIs: Access to agricultural markets for both inputs and sales is a challenging issue for smallholders and the situation is far worse in remote schemes, where farmers have no infrastructure to reach other markets. Isolated smallholder schemes are exposed to market monopolies such as fertilizers' distributors. As agricultural inputs are crucial factors to improve WP, appropriate products should be provided to farmers. Based on the identified constraining factors, the following instruments are recommended:

- Certified merchandizing of inputs: farmers have little knowledge about the accessibility and applicability of different agricultural inputs. In order to avoid the misuse of fertilizers and the use above profitability threshold, centralized support should be provided for them. Certification of merchandizers would help farmers selecting the quality inputs.

- Advisory system on fertilizing: although farmers apply relatively low amount of fertilizers, its cost is significant in the overall cost structure. Advisory systems of fertilizers should be established in decentralized manner to better involve farmers in knowledge sharing.

\section{On-farm irrigation issues}

In Ben Nafa Kacha irrigation scheme, the OUEA manages the water supply up to secondary canal level. The main canal is connected to six secondary canals, each one providing water by rotation to five tertiary canals, thus, the total number of tertiary canals in the considered area is 30 . The majority of these tertiary canals (25) provide water to 10 ha each, while five tertiary canals irrigate only 5 ha each. While the canals are lined at main and secondary levels, tertiary canals and drains are small earthen canals, causing a significant decrease in water use efficiency at tertiary level. The water service is established according to a fix rotation schedule, consisting of a water turn every five days with a duration adjusted by the farmers at tertiary level, based on an informal agreement among farmers. It is fairly frequent for farmers to siphon or pump water directly from the main or secondary canals. This is due either to the farmers missing their irrigation turn and hence by-passing the intake structures (modules à masques), or to water not reaching with sufficient flow all the plots located at the downstream end of the tertiary canals. 
At farm level, water is applied by furrows to maize and horticultural crops and by basin irrigation for rice. Waterlogging problems occur frequently and negatively affect maize production during the rainy season, when ensuring good drainage is, thus, critical. The drainage systems at farm level should be improved and maintained, and their connections with the general drainage system need to be also ensured. Furthermore, a general lack of uniformity was observed in the rice fields mainly due to inadequate land levelling. The low mechanization of the scheme is the prevalent constraint to the significant improvement of on-farm irrigation, yet farmers have no means to carry-out proper levelling, riding, and further land works.

The water supply is distributed through dictated rotation, which results in large water deliveries per time. Although farmers usually vary the irrigation duration as a function of the crop phenological stage, some improvements could be achieved in irrigation scheduling, especially in maize and onion, with room for improvements in both timing and irrigation depths. The irrigation schedule at farm level should be consistent with the crop water requirements, particularly for maize and onion. When the water supply is limited, it is important to concentrate irrigation in the critical crop stages, i.e. those most sensitive to water deficits. Farmers, thus, need to be trained on which are the critical stages of each crop and on the need to supply sufficient water during those stages.

Issues related to the irrigation development are also included in the PNSR II, specifically in the third sub-programme of the Axis 1 , with the objective to ensure and secure the availability of surface and groundwater for the sustainable development of agricultural production. However, actions aimed at the improvement and promotion at the scheme level. A vision for irrigation management at field level, pursuing training of farmers on irrigation management, for instance, or measures for mechanized land levelling, is not contemplated. Only Action 4 focuses on ensuring efficient management and increasing water productivity through the implementation of appropriate techniques and equipment (drip irrigation) for the development improvement.

Recommended WPIs: Irrigation practices are the most relevant factor for the improvement of WP. In spite of sufficient water resources, irrigation practices are often not appropriate to exploit WP potential. Based on the identified constraining factors, the following instruments are recommended:

- Crop demand based irrigation scheduling: farmers currently irrigate in dictated rotation that is often too rigid to adjust water supply to water demand. Moreover, most of the farmers have insufficient knowledge about the changing water demand over crop growth periods. Irrigation plan should be developed for farmers, based on well-established irrigation schedule.

- Improved mechanization of land works through micro-loans: smallholders are constrained by their resources. Purchasing heavy equipment is not feasible on individual bases, although, WP could be increased through better land preparation. Farmers' cooperatives, on the other side, can be financially stable to apply for micro-loans and extend their services with machine works. Enabling the environment for mechanization of irrigation schemes would essentially improve the quality of land works in small-scale schemes. 


\section{Concluding remarks}

- The isolation of the area and the high costs of agro-inputs make it difficult to improve profitably of both staple and cash crops. The fixed rotation schedule, the status of the irrigation system and the cost of pumping irrigation water are specific issues of the selected area, yet quite common in this type of irrigation schemes.

- Actual and attainable yields for the irrigation scheme were measured and calculated based on extensive work using the AquaCrop simulation model, locally calibrated for several crops. The yield gaps were also estimated, identifying the possible causes to reduce them in each case. Field guides were developed and disseminated to technicians and farmers.

- In order to improve irrigation management at farm level, it is essential to link water productivity theme with water use efficiency theme to identify measures to enhance the water service, including reduction of energy costs, the maintenance of secondary and drainage canals, and improved irrigation scheduling by matching applications to crop needs rather than following a rigid calendar. Together with WP measures, this will comprehensively lead to optimal practices to improve irrigation management at farm level.

- According to the PNSR II and the sub-programmes of sustainable development of agricultural production and hydro-agricultural development, capacity-building was organized for national technicians specifically addressing the aspects related to the methodologies and protocols for the implementation of the good agricultural practices. Furthermore, the project introduced FAO's crop growth simulation tool (AquaCrop model) to establish management rules, increasing the capacity of professionals and supporting decision-making related to irrigation and other agronomic practices. Effective coordination among research organizations, extension agencies, producer cooperatives, and WUAs being a key factor in overcoming the water productivity gaps, was established by the project.

\section{Morocco: coping with water scarcity}

According to World Bank's predictions, the Near East and North Africa (NENA) region will experience the most significant economic losses by 2050 from climate-related water scarcity and Morocco, as part of the region, is a country constantly threatened by water scarcity. Measures to improve water productivity in agriculture, the primary user of water in the region, are therefore, of capital importance.

The area selected for assessment in Morocco lies in an irrigation district located in the Haouz plain, which is part of the Tensift Watershed, in Central Morocco. It is characterized by an arid, Mediterranean type climate, with an average annual rainfall of about $250 \mathrm{~mm}$, distributed over a wet season spanning from October to April, and a completely dry season from May to September. The selected area, the R3 Sector-AI Haouz Irrigation Scheme, covers around 2800 ha located $40 \mathrm{~km}$ east from Marrakesh city, and it gathers 310 farmers distributed over three Water User Association (AUEAs). The scheme receives water by the Hassan II Dam through the Rocade Canal, feeding two primary canals: $\mathrm{P} 1$ on the right bank of the sector and P2 on the left bank. The R3 Sector is equipped 
with semi-circular elevated canals irrigating by gravity mainly winter cereals for seed production, olive trees, and some vegetables and fodder crops. Until recently, the irrigation method was exclusively by surface (border irrigation), but provisions included in the PMV and related PNEEI, led to the installation of several drip irrigation systems in some farms in recent years. Notwithstanding the remarkable public financial support for the conversion to drip irrigation in Morocco, in this area it is limited to horticultural crops and intensive olive orchards. At the same time, it is expected that the area devoted to cereals for seed production will remain stable due to its steady profitability and low risks. The Regional Office of Agricultural Development of Haouz (ORMVAH) manages the distribution of irrigation water as a function of the water availability in the Hassan I Dam, in coordination with the Tensift Basin Agency (ABH-Tensift) and the AUEAs.

\section{Cereals for seed production}

According to the cropping patterns, three main categories of farmers were identified in the R3 Sector-Al Haouz Irrigation Scheme: (i) farmers specialized in cereal seed production; (ii) traditional farmers growing cereals, olive trees and alfalfa (the latter required to feed their livestock); and (iii) entrepreneurial farmers that are developing intensive olive and citrus orchards. Only 15 farmers grow cereals for seeds production (70 percent of durum wheat - Karim, Marzak and Saragola varieties -, 20 percent of bread wheat - Achtar and Marchouch varieties-, and 10 percent of barley Amira variety), occupying about 60 percent of the area $\mathrm{R} 3 \mathrm{P} 2$, on the left bank. The cropping system is continuous cereal, with no crop rotation (cereal/cereal or cereal/fallow/cereal). The farmers following this cropping system are locally based and seed production oriented and receive steady incomes through contracts signed with the National Seed Marketing Company (SONACOS Maroc). Additionally, a small number of farmers also grow cereals (wheat, barley and maize as a forage crop) in rotation with some vegetable crops, mainly potato.

SONACOS, under the supervision of the Ministry of Agriculture, is a key and strategic stakeholder in the certified seed production value chain. This Agency brings together a set of integrated activities, involving various institutions, such as the National Institute of Agronomic Research (INRA) in the breeding programme, private companies in a contractual framework for seed multiplication, and the National Office of Food Safety (ONSSA) for the control of the seed value chain and the seed certification granted to growers. Given the importance of the seed sector as one of the main lever for achieving the objectives of the PMV, the State, the Moroccan Association of Seed Multipliers (AMMS) and the Moroccan Association of Seeds and Plants (AMSP), concluded, a programme contract for the period 2009-2020 that lays out the guidelines for a quality seed production. Moreover, the programme promotes policies for the improvement of the rate of use of certified seeds and the increase of participation of different stakeholders in the national production of certified seed.

Although yield levels achieved in the cereals cropping systems result acceptable, there are opportunities for improvement. This is particularly relevant in the case of cereals for human consumption, as can be seen in Figure 18, where the average yield is low if compared to the cereals for seed production. Probably, a major reason for these differences lies with the technical support 
that seed producers receive, as the technicians of SONACOS and ONSSA provide assistance and technical advice by visiting the farms two and three times along the growing season, respectively. The other cereal producers, while attempting to follow their practices, do not receive any direct advice. Albeit their relatively high yields, seed producers are aware that they could get even higher yields by improving water and soil fertility management. Alike the efforts undertaken by National Office of Agricultural Council (ONCA) in other irrigated areas, Haouz farmers demanded demonstration plots in the area where training visits could be carried out.

Figure 18: Evolution of the average yield for cereals in Sector R3P2

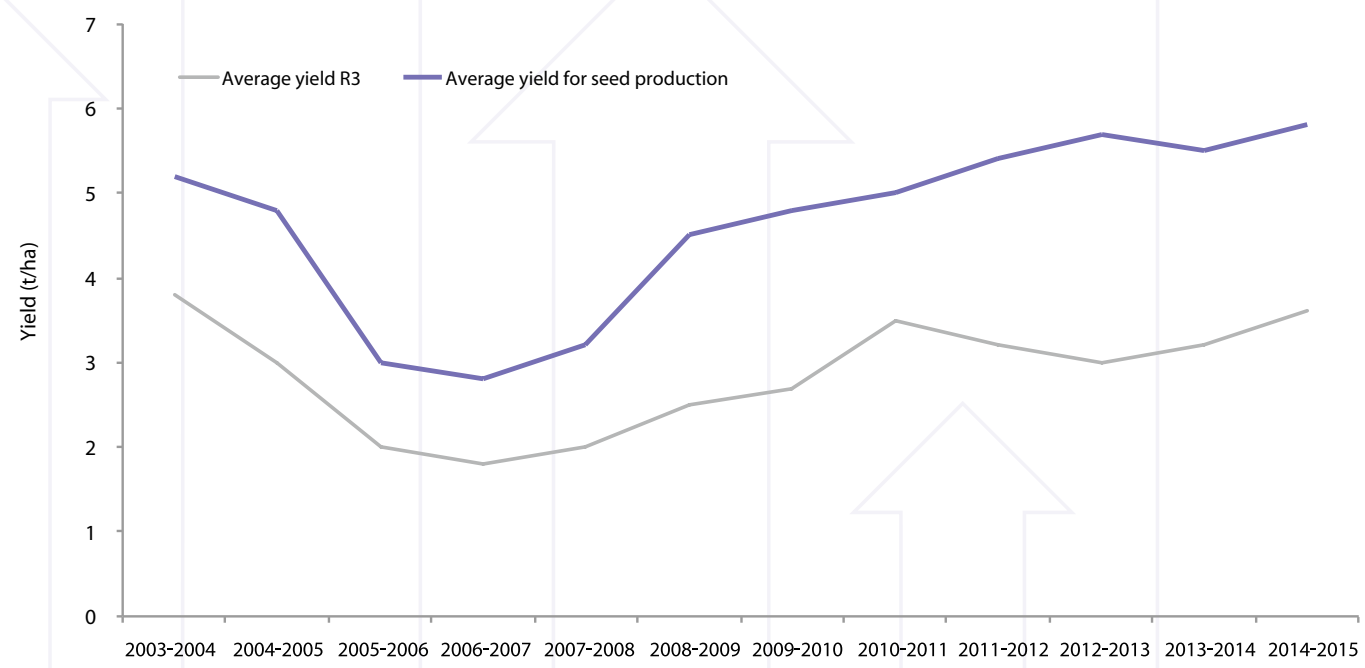

Source: ORMVAH, 2016

Recommended WPIs: Morocco has established a well-functioning advisory system for crop production. Seed production is at the heart of agricultural development programmes thus providing high-yielding varieties along with appropriate recommendation on practices. However, not all the farmers are able to access such programmes and the diversity of water and soil fertility, besides, is widely-ranging, which requires customized advisory systems at scheme level. Based on the identified constraining factors, the following instruments are recommended:

- Locally customized extension services: Based on the current framework of extension services, customized services should be provided to involve more farmers and to extend the applicability of services.

- Participatory approach of extension services: The inclusion of civil society, i.e. communitybased, farmers-based and non-governmental organizations, in the provision of irrigation advisory services should be increasingly taken into consideration as an effective means to enhance the direct dialogue between institutions and direct beneficiaries. 


\section{Irrigation water supply and demand: threats to the sustainable use of groundwater}

The periodic drought and the expansion of irrigation pose a threat to the sustainability of water resources, particularly that of groundwater, and irrigation associations (AUEAs), in this respect, play a significant role in the distribution of water allocation and in irrigation scheduling. Managers and users (5 farmers' representatives) decide on the number of irrigation turns and irrigation water amount assigned under every irrigation turn. Although water distribution at tertiary level is in the hands of the farmers' association (each tertiary channel irrigates about $40 \mathrm{ha}$ ), individual farmers stressed some equity problems at this level. The average annual water allocation is about $4000 \mathrm{~m}^{3}$ / ha, with a monthly frequency supply, according to the crops and rotations adopted by farmers. However, the fields devoted to cereal seed production have priority over other crops in case of water scarcity, with irrigation intervals of 12-15 days, applying an average of 5-7 irrigations per season. Despite some flexibility to change the irrigation turns during the growing seasons, the limitations of the water service become an issue for farmers, particularly for those employing drip irrigation systems. This condition, along with the fact that the high-frequency irrigation system is used in conjunction with high water demanding crops during the period of highest atmospheric water demand (e.g. maize and melon), have forced farmers to seek alternative water supplies, such as groundwater. Hence, the groundwater resources of the R3 Sector are facing high pressure and the water table level is decreasing by about $1 \mathrm{~m}$ per year. On the other hand, it is also probable that the reduced employment of surface irrigation systems in the area may decrease the aquifer recharge, as the natural deep percolation losses that occur under surface irrigation are mostly avoided by drip. The over-exploitation, the high cost of pumping (about $100 \mathrm{~m}$ depth) together with the high salt content in the groundwater ( $E C$ is about $5 \mathrm{dS} / \mathrm{m}$ ) pose a threat to the sustainable exploitation of groundwater for irrigation management in this area.

The PMV, with its subsidy policy for shifting to localized irrigation through the PNEEl, focuses on the concepts of raising productivity, rural incomes and "water saving" through efficient water use, although the medium-long term effects on groundwater may be just the opposite. This is attributed to the fact that crop water consumption as ETc generally increases under situations of low productivity and low irrigation efficiency.

Water balance at basin level shows that the conventional water policy alone cannot guarantee water supply in the long term. Whatever the alternatives chosen, it is and it will be necessary to take measures to manage water demand to reduce deficits, and this is what is addressed by the National Water Strategy (SNE). With regards to groundwater, the strategy proposal in the medium and long term is based on the establishment of sustainable management mainly through:

- the limitation of pumping and the strengthening of control and monitoring system, in the context of groundwater contracts; and

- the use of artificial recharge of water table. 
To ensure the successful implementation of this strategy, accompanying measures have been planned by implementing the provisions of Water Law 10-95. Moreover, in order to address the issues of groundwater over-exploitation and ensure their sustainable management, River Basin Agencies $(\mathrm{ABHs})$ are called to prepare action plans for groundwater management that include technical, regulatory and institutional measures. Their objectives are to reduce over-exploitation, which results in external costs collectively borne by users, and to address the non-optimal allocation of resources, which only favours short-term profitability for sustainable agricultural production.

Recommended WPIs: Morocco is currently facing severe water scarcity, which exacerbates into drought. The water saving interventions, such as irrigation cease, force farmers to look for alternative solutions. They are, thus, increasingly relying on groundwater sources, a condition that leads to an overall imbalance between renewable groundwater resources and water withdrawal. Based on the identified constraining factors, the following instruments are recommended:

- Groundwater use through water accounting approach: Water resources must be carefully accounted in order to ensure sustainability. Groundwater resources should be mapped and governance measures should be introduced to maintain their recharge. A water accounting approach would certainly strengthen long-term sustainability of water use, thus, ensuring a sustainable level of WP.

- Roadmap of alternative irrigation practices: WP can be improved through different irrigation practices, such as deficit irrigation. Although farmers sometimes need to compromise with yield, such practices help sustaining water requirements without major production failure. A roadmap of irrigation practices should be compiled with well-demonstration impact assessment on yield and other farming outcomes.

\section{Surface and drip irrigation in olive orchards}

In 2016, Morocco reached the goal of one million hectares of olive trees, thanks to the efforts made as part of the agricultural policy PMV. About 35 percent of the olive area in the country is irrigated, with traditional flood irrigation employed over 90 percent of this area. The upward trend in the sector, both in Morocco and in the whole Mediterranean area, necessarily leads to an increase of production through the use of intensive plantations. These new production systems are also associated with the expansion of the drip irrigation system. Despite huge efforts carried out over the last years by the production sector towards intensification, cultural issues related to traditional rainfed crop management know-how prevented farmers from adopting sustainable irrigation management practices. However, the management of water resources has now become a key issue, especially in regions facing water shortages. The conversion of a cropping area from surface to localized irrigation faces a complex process that requires considering both individual and collective aspects of irrigators, as shown in Figure 19. 
Figure 19: Steps for conversion from surface to localized irrigation

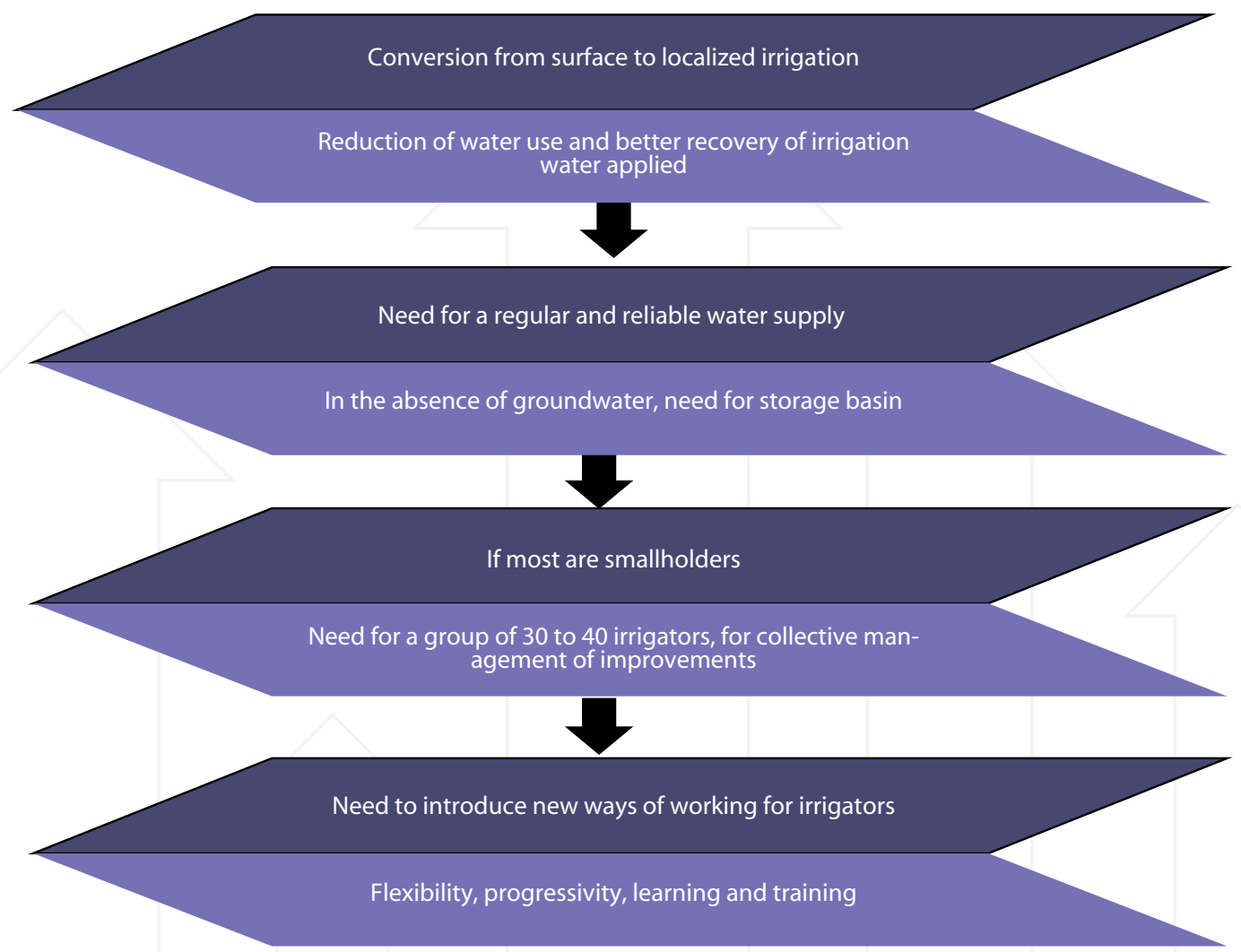

Source: adapted from FAO $2012 b$

Currently, two types of production systems for olive trees coexist in the R3 Sector-Al Haouz Irrigation Scheme: traditional orchards surfaced irrigated (border irrigation) with low or medium tree densities (100 to 250 trees/ha, farms less than 1 hectare) on one side, and intensive orchards (more than 1000 trees/ha, more than 20 hectares), drip irrigated with on-farm reservoirs to store water from the canal and mix it with groundwater on the other. The intensive orchards, established by entrepreneurial farmers, demand high amounts of water resources and for this reason there is an increased request for advice on efficient on-farm management of water and nutrients under the local conditions and especially under future water scarce scenarios.

The main objective of irrigation scheduling is to avoid trees' water deficits that would negatively impact production. Therefore, the main challenges for an efficient irrigation strategy in olive orchards are: a) determining the full trees' water needs; and b) defining and tailoring the best irrigation schedule (full irrigation or deficit irrigation strategies) in terms of net profits by taking into account the current water availability and particular conditions. The first step, thus, is to estimate the olive water requirements under the particular environment and for the specific orchard 
characteristics (e.g. tree density, canopy volume, etc.) The 'water budget method' is the simplest and most widespread approach to apply. It employs estimations of soil water-storage capacity (TAW), allowable water depletion, and crop evapotranspiration (ETc). Once the ETc is calculated, the irrigation requirement can be estimated by the subtraction of effective rainfall from the total crop water demand (ETc). The second step is then to design the best irrigation schedule adapted to local conditions. In water scarcity situations, recurrent in Morocco, irrigation scheduling becomes more complex, as water supply is usually insufficient to meet full olive orchard demand. In the case of the project area, the irrigation water allocation is approximately $400 \mathrm{~mm} / \mathrm{year}$, less than the full irrigation needs of mature orchards in most years (about $600 \mathrm{~mm}$ ). Therefore, irrigation scheduling needs to be carefully designed to optimize trees' water use. When water supply results insufficient, as in the case of the project area, the only option is to apply less water than the orchard ETc requirements, a strategy known as deficit irrigation (DI). On the other hand, and in the case of olives, $\mathrm{DI}$ is often the best strategy for maximizing revenue. However, since water deficits may lead to reductions in yield, it is important to consider the sensitivity of olive trees to water stress in each particular phenological phase.

Recommended WPIs: Recent agricultural tendencies support the intensification of production. This is particularly the case in olive production. The more intensive agriculture goes often in hand with more water requirement. In water-scarce environment, appropriate irrigation management methods of intensive production is crucial to cope with water scarcity while at the same time supplying sufficient water. Based on the identified constraining factors, the following instruments are recommended:

- Water requirement based irrigation scheduling:The existing irrigation scheduling methods are numerous, however, proper scheduling is often neglected, which results in considerable water loss without providing yield gains. Irrigation scheduling is particularly important in water-scarce environment, where it is essential to adapt water supplies to critical crop stages. While introducing modernized technology, establishing irrigation plan is necessary. Although farmers in Morocco have access to extension service, further capacity-building should be provided to help farmers establishing irrigation plans.

\section{Concluding remarks}

- Agriculture in Morocco is going through an intensification process, promoted by development policies, mostly outlined in the PMV. Regarding the improvement of irrigation management, the PNNEI has encouraged the conversion from surface to localized irrigation. Nevertheless, this conversion, while reducing losses, is leading to increased water use, commensurate with the increase in irrigated area and in productivity. Farmers who have adopted the new irrigation system need to receive advanced technical support. Therefore, there is increased demand for advice on efficient on-farm management of water under local conditions, especially under future scenarios of water scarcity and groundwater overexploitation.

- Actual and attainable yields for the irrigation scheme were measured and calculated using 
FAO AquaCrop simulation model that was locally calibrated for cereal crops. As for olive production, an empirical production function was used instead of AquaCrop model, which relates yield to water consumption (ET). The yield gaps were also estimated, identifying the possible causes to reduce them in each case. For both olive orchard systems, surface and drip irrigation, their water requirements and irrigation scheduling were evaluated and estimated, proposing deficit irrigation strategies.

- In order to increase WP, other optimal farming practices, such as actions on fertilization management, plant protection and pruning practices were also recommended. Field guides were developed and disseminated to technicians and farmers.

- For the enhancement of the WP at farm level, it is desirable and necessary to involve all the key stakeholders (farmers, AUEAs, ORMVAs, ABHs, ONCA, etc.). Large investments may be threatened by over-exploitation of groundwater resources. The strategy established by the SNE and law enforcement are determinant factors to control and limit the further expansion of intensive irrigation against available resources, ensuring their compatibility, based on a more accurate and operational water accounting at basin level.

\section{Uganda: abundant resources}

The Kasese district is located along the Equator in the western region of Uganda, bordering with the Democratic Republic of Congo. The region is characterized by a tropical climate and an annual precipitation that follows a bimodal pattern, with peak rainfall periods from April to May and from October to November. The average annual rainfall is about $880 \mathrm{~mm}$. Close to Kasese town, the Mubuku Irrigation Settlement Scheme is located downstream from a range of high mountains (Rwenzori Range) and upstream from Georges Lake. The potential irrigable land is about 2000 hectares but the current rehabilitated area under use is approximately 540 hectares. There are 167 farmers registered with an average of 8 acres ( 3.2 hectares) /farm holding. Sixty percent of the area is devoted to maize and upland rice for seed production, favoured by the Cooperative Society, while 40 percent is for horticultural crops (onions, tomatoes, hot peppers, beans, tree crops, etc.). The irrigation system is made of two branches that are diverting water on the right side of the River Sebwe. The upstream branch is a canal system whereas the downstream branch is a pipe system. The system is divided into a set of 13 divisions or blocks.

\section{A suitable crop rotation and land preparation}

The climatic conditions in the area allow two growing seasons per year. Most of the farmers grow maize after rice in their fields, or even repeat the same crop (maize after maize or rice after rice). These cropping patterns reflect the economic relevance of these two crops, as well as the contracts signed with the cooperative society. Rarely, cereals are grown in rotation with onions or bush beans. As concluded by the project, suitable crop rotation is deemed to be an important strategic action. Other major advantage of rotations is the opportunity to implement sustainable pest, disease and weed management programme that disrupts pest and disease cycles (e.g. rice stem borer) and include smothering crop species (e.g. beans) to help weed control. Rotations also 
improve soil fertility and quality (nitrogen fixation, better distribution of nutrients in the soil profile, more or deeper roots, beneficial root exudates, biological activity, etc.). Nevertheless, rotation needs to respond to farmers' needs, whether it be for cash income (contracts for maize and rice and/or incomes from onion marketing) or for subsistence (small area devoted to cassava, vegetables, etc.). Figure 20 shows the profitability of the main crops in poor and high market conditions. Depending on the supply in the market, the price fluctuation varies consistently. Except maize, both rice and onion can significantly lose market value over production period. Therefore, farmers' crop selection must consider both market and field risk.

Figure 20: Profitability analysis in poor and high market conditions for Mubuku Scheme

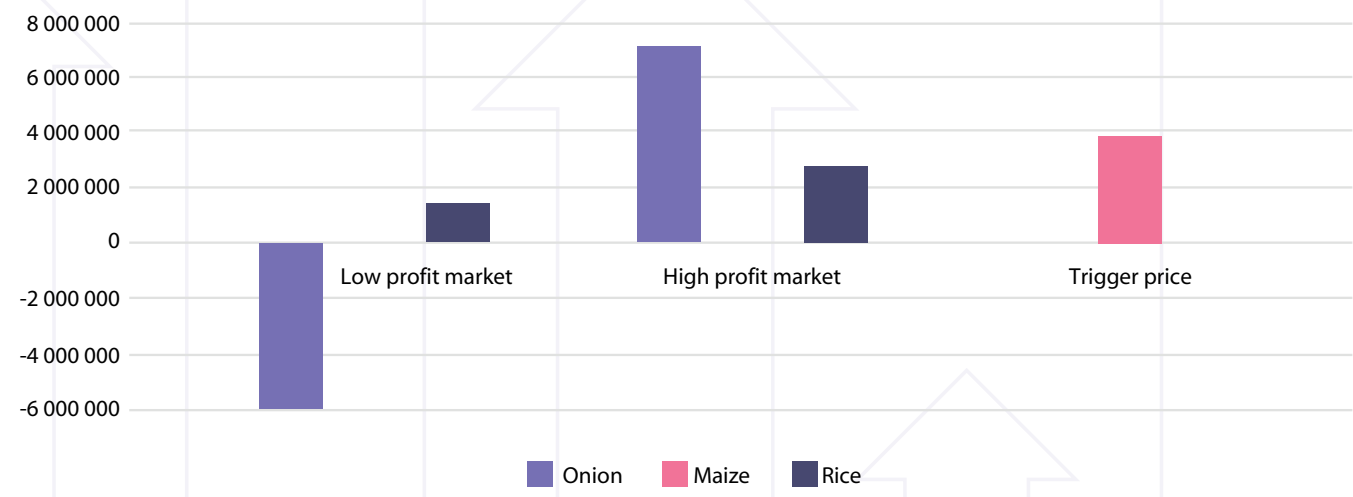

Currently, furrow irrigation is the only irrigation method applied in Mubuku Irrigation Scheme, where the poor land levelling represents a major issue for irrigation management at farm level. Although levelling costs are not high, around 50 USD/ha and equivalent to only about 6 percent of production costs, it is not a common practice. Yet, most of the farmers in the scheme consider land levelling one of the most effective technique to improve irrigation management. Moreover, improvement in the irrigation distribution uniformity is highly required, since problems of low irrigation uniformity, associated with inappropriate ridging, were found in some farms. Other factors related to land preparation were also considered, such as the soil moisture condition at sowing to ensure a good crop establishment, and a good seedbed preparation, also for successful crop establishment and, therefore, for an optimal growth and development throughout the growing season. The agricultural cooperative is mechanized and it provides services of heavy equipment. However, the low profitability of crops does not allow regular purchasing of land work services. The survey carried out amongst farmers showed that farmers have high demand on land work, as well as on advisory function, agronomic input function and better water services (Table 6). 
Table 6: Differences between provided and requested services in the scheme

\begin{tabular}{llll}
\hline Cooperative services & Provided service & Basis of entitlement & Famers' request \\
\hline Advisory function & Yes & Personal application & High demand \\
\hline $\begin{array}{l}\text { Agronomic input function } \\
\text { (fertilizer, seeds) }\end{array}$ & Yes & $\begin{array}{l}\text { Personal application (for } \\
\text { maize producers) }\end{array}$ & High demand \\
\hline Water service & Yes & Total area cultivated & High demand \\
\hline Machinery rent & Yes & Personal application & Middle request \\
\hline Human services & No & - & Low demand \\
\hline Land work & No & - & High demand \\
\hline Marketing & No & - & No demand \\
\hline Post-harvest technology & Yes & Total area and crop cultivated & Low demand \\
\hline Storing infrastructure & Yes & Total area and crop cultivated & No demand
\end{tabular}

Within the 2015/16 to 2019/20 ASSP, Priority 2 "Increase access to critical farm inputs" (35 percent of total budget) includes strategies to promote agriculture mechanization and improve access to high quality seeds, planting and stocking materials. All of these measures should contribute positively to enhancing agricultural productivity.

Recommended WPIs: Although farmers have access to land work services, the low-profitability of crops often do not allow farmers to take additional costs. This results in poor land preparation practices and lower water productivity. Based on the identified constraining factors, the following instruments are recommended:

- Subsidized agricultural mechanization service centre: Farmers' access - both physical and "economic" - to agricultural machines should be facilitated. Farmers have limited resources to purchase machines, therefore, centres should be established, or, in alternative, already existing cooperatives, associations, extension services should be subsidized by economic instruments (interest-free loans, etc.) to upgrade their machine yard, and provide cheap services for farmers. Such instrument would also help farmers transition away from staple crop production toward commercial agriculture.

- Enhanced capacities on land preparation: Although farmers have long-term experiences in land preparation, some of the traditional practices are not sufficient to increase WP. In order to unlock the access to information, extension service should include capacity-building on land preparation through on-site training. 


\section{Issues of irrigation practices: imbalanced equity}

The lack of control in the frequency, duration and volume of water supply in the irrigation scheme, together with the low application efficiency leads to lower than expected productivity and causes inequity in the distribution of irrigation water among farmers.

At scheme level, the cooperative society of Mubuku integrates the WUA function, being responsible for the operations and maintenance of the irrigation system up to the secondary canal level, but the lack of discharge measuring and control systems at head canal leads to massive amounts of water entering the scheme at times. At farm level, the poor state of the hydraulic infrastructure at the tertiary and quaternary canals causes a deficient irrigation water supply and problems of waterlogging in some farms that affects water productivity. Excessive runoff, high soil erosion rates, and leaching were the most critical issues detected, while the reduction of discharge flow should also be contemplated, in order to improve water application efficiency. Besides, the hired irrigators should be trained to carry out irrigation in the most effective way.

On the other hand, due to the shallow root system of some crops (e.g. onion), the limited current water service in some areas (low frequency and duration) induces water stress to the crop during specific periods. Under the current water service, most farmers can only water one block per irrigation event, irrigating each block around every 16 days, a clearly excessive period at certain times for a shallow rooted crop such as onion. The improvement of the water service is, thus, crucial, in order to facilitate the increase in frequency of application to some crops, and to enhance water management at farm level in line with it (Figure 21).

Finding optimal solution for irrigation practices is further complicated with the multi-cropping system, which creates a spatial dispatch of water requirement over the scheme. Moreover, a great heterogeneity in water availability among tertiary canals is revealed, while, the irrigation schedule at farm level should instead be consistent with the crop water requirements, and not only dependent on the timing of water delivery. It is particularly important to concentrate irrigation in critical crop stages, i.e. those most sensitive to water deficits. Furthermore, drainage systems at farm level should be improved and their connections with the general drainage system need to be also ensured. Under the project's framework, waterlogging effects were mitigated by digging a drainage channel from the upper side of the field down to the bottom in order to connect it with the general drainage system.

Although creating equity amongst water users relates to WUE, inequity has direct effect also on WP. The currently extending irrigation scheme must be able to provide equal water services to the newly annexed lands. Within-system inequity exposes farmers to lower water productivity in the downstream areas. 
Figure21: Proposed methodology for improving water service through WUEWP components in Mubuku

\section{Diagnosis phase}

Interviews aimed at farmers and irrigation officers to understand the current water service

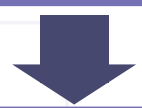

\section{Inequity among farms and low application efficiency}

Maintenance problems and lack of water flow monitoring. Problems with hydraulic infrastructure at plot level (deficient water supply, water stress and waterlogging)

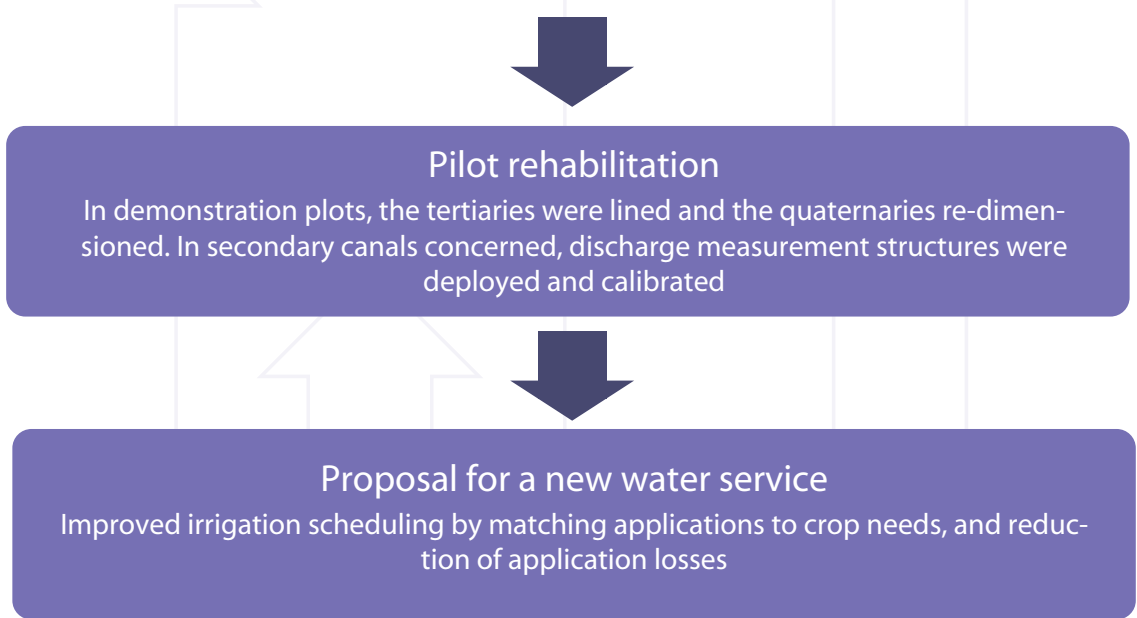

WUE and WP themes are strongly interlinked within the existing water policies in Uganda. The ASSP includes strategic interventions to increase access to water for agricultural production, and other productivity enhancing measures. The National Irrigation Policy (2017) lays out the guiding principles and general institutional arrangement for irrigation development and management, including coordinated planning, implementation, and service delivery, as well as cost recovery and beneficiary participation through WUAs. The National Irrigation Master plan (MWE 2011-2035) indicates the priority irrigation development areas and schemes over short, medium and long terms.

Recommended WPIs: Although the system has abundant water resources, the WP shows heterogeneity amongst farmers due to unequal water services. WP is directly affected by the system-level water services. Irrigation practices can be improved through better water services. Based on the identified constraining factors, the following instruments are recommended: 
- Flexible water services: Irrigation practices easily fall short on providing sufficient water in appropriate time if the system-level water services are not flexible enough. Flexible water services should be introduced at system level to support farmers in creating irrigation plans.

- Water requirement based irrigation scheduling: Irrigation is based on dictated rotation that leads to temporal water stress, in particular for shallow rooted crop. Effective tools should be introduced for cooperatives, farmers associations, extension services to facilitate the crop-requirement based scheduling.

\section{Concluding remarks}

- Increasing food security and ensuring transition from subsistence to commercial farming have been the main challenges of Ugandan agriculture in recent years. Apparently, water is not a limiting resource in many production systems, but improved water management at scheme level can enhance productivity and address several issues, such as inequity among farmers. The current irrigation management is not effective enough to control water flows and deliveries at farm level. High efficiency is difficult to achieve (runoff increases rapidly) and also irrigation needs to be cut-off rapidly. In addition, poor land levelling does not allow a uniform distribution of irrigation water. Moreover, substantial limitations were noted in the access to adequate good quality inputs (seeds, fertilizers, pesticides, etc.).

- Actual and attainable yields for the irrigation scheme were measured and calculated through the employment of FAO AquaCrop simulation model, which was calibrated locally for several crops. The yield gaps were also estimated, identifying the possible causes to reduce them in each case. Aligned with WUE instruments, a proposal of a new water service was designed, which allowed matching crop needs with adequate irrigation water delivery periods, and reduction of application losses. Field guides were developed and disseminated to technicians and farmers.

- Once more, the coordinated work of WUE and WP proved fundamental to develop recommendations for the improvement of irrigation management at farm level. It is essential to delineate the measures to enhance water service, including reduction of the amount of water supply, adequate maintenance of tertiaries and drainage canals, and improved irrigation scheduling by matching applications to crop needs rather than following a rigid calendar. Optimizing farming practices -such as appropriate land preparation, suitable crop rotation, improvement of mineral fertilization, better management of weeds, pest and diseases- allows the intensification and diversification of agricultural production in these cropping systems.

- Following the water policies and agricultural development strategies framed in the NDPII, the National Irrigation Policy, the Irrigation Master Plan and in particular the ASSP, capacitybuilding was organized for national technicians, particularly focused on the aspects related to methodologies and protocols for the implementation of good agricultural practices. Priority 1 and 2 of the ASSP, with their respective strategies, include specific actions to increase agricultural production and productivity. In addition, to facilitate the establishment 
of management rules, thereby increasing capacity and supporting decision-making related to irrigation and other agronomic practices, a companion tool (the AquaCrop model) was introduced. Furthermore, a ground for effective coordination amongst all the organizations involved has been established to enable the environment for the scale up to other schemes and overcome the gaps in water productivity. 


\section{Synthesis of policy recommendations}

Previous sections presented the case-specific recommendations on improving WP. However, there are general inferences, which are relevant for countries considering to mainstream WP into national strategies. The following recommendations can be tailored to areas with similar environmental, socio-economic and irrigation management conditions.

Drawn from the results of the activities performed in three pilot irrigation schemes in Burkina Faso, Morocco and Uganda under the framework of the FAO project "Strengthening Agricultural Water Efficiency and Productivity on the African and Global Level", a synthesis of key messages for policy makers to improve WP is presented. The recommendations provided aim also at ensuring a positive impact on agricultural production and on the conservation of water resources. Ultimately, the goal is to guide effective planning at policy level and to ensure sustainable irrigation development.

\section{Establishment of relevant methods to map WP potential}

To improve WP, it is necessary to determine the baseline or current status of WP in a given system (herein called actual WP) and the maximum or attainable WP value that can be achieved under these specific conditions. This is essential to have a realistic picture of every situation before proposing WP improvement measures. The potential for improvement can be quantified by defining WP gap. Quantifying the gap in WP is fundamental for a number of reasons: i) to identify the causes of the WP gaps; ii) to propose management strategies to close the gaps, and iii) to delineate and propose policies that will enable the closure of the gaps.

\section{Capacity building of on irrigation practices}

It is common to find irrigation technologies and infrastructures poorly performing due to inadequate operation or maintenance. The lack of skilled technicians specialized in irrigation accentuates this issue. Centralized support should be promoted through irrigation courses and training programmes, in order to orient technicians and extension officers towards better design, operation and maintenance of the irrigation systems.

\section{Flexible water allocation according to crop needs}

Water policy should ensure that sufficient water is allocated to provide crops their needs and at the same time ensure the highest possible ecosystems' protection, by keeping them healthy. In addition, a secure and equitable access to water should also be guaranteed to all farmers of 
irrigation schemes. Thus, for a proper water allocation, all stakeholders should be involved in water resources and ecosystem management, and trained to improve their understanding of systems, as linked to a precise estimation of crops water needs in each system.

\section{Re-visited collective organizations}

A common solution to water management in irrigation schemes has been to hand over control to farmers' organizations or WUAs. Such organizations are generally represent the small irrigators' community. However, they can, at times, obscure inequality and conflicts within the schemes, hampering an optimum irrigation water management. Furthermore, a predisposition for collective irrigation management practices should not be assumed. Government policy makers should promote a performance improvement of WUAs. Legal and contractual adjustments have proven not to be effective and alternative models should, thus, be explored, such as: (a) Joint management - government agencies working closely with WUAs-; (b) Multifunctional WUA - developing other services besides water management-; and (c) Public-private partnership - WUA entering into a contract with a private entity-.

\section{Improved technical extension services for farmers}

As appeared evident in the three pilot irrigation schemes, farmers are not sufficiently aware of crop response to water, the basis of irrigation scheduling, on-farm water application techniques and even general agricultural practices (plant density; fertilization practices, pests and diseases control, etc.). As expected, this knowledge gap results in low crop WP. This low capacity of farmers related to irrigation water management is limiting the potential of the existing irrigation infrastructures. In the absence of robust and coordinated extension services, it is necessary to improve the public local advisory services, ensuring a well-coordinated network with skilled technicians. These extension services should be based on the approaches 'learning by doing' and 'lead farmers', since farmers learn from one another by observation. In line with this, extension activities should take place in situ, with a greater use of on-farm training activities, rather than off-farm activities. Farmers' cooperatives and farmers-based organizations can also play an important role in this network of advisory services.

\section{Promotion of low-cost irrigation technology}

Low-cost irrigation technologies should be promoted for smallholder farmers to increase water productivity. These technologies are easy to use, thanks to a simple design, and less labour intensive, thus represent an attractive option for small farmers. A clear example of this technology is the Siphon tubes, which proved to be an effective technology for furrow irrigation applied within the project framework. They are used to ensure a better control of furrow discharge flow, by reducing the runoff and soil erosion problems. At the same time, they can decrease the irrigation application time, allowing enhancing irrigation frequency in sensitive crops. 


\section{Facilitated access to agricultural inputs: fostering local private enterprises}

The majority of small irrigation schemes in these countries are located in distant rural areas, with difficulties in transportation due to the poor state of roads. In addition, the agro-inputs needed to enhance the crop WP (irrigation spare equipment, seeds, fertilizers, pesticides, etc.) are costly or inaccessible; while their quality is another key limiting factor. Therefore, governments should take action to ensure that farmers have access to agro-inputs of the right quality. Fostering local private enterprises that facilitate the acquisition by farmers of proper agro-inputs might be an effective step.

\section{Improved WP through economic instruments}

Although the creation of farmers' cooperatives brought significant improvements in product marketing, thus fostering increased farm incomes, deficiencies in payment process and credit access were detected in the pilot irrigation schemes. The frequent late payment of the products led to a situation whereby farmers cannot meet the costs of the new season, being forced to apply for credits. Often, farmers have limited access to credits or other financial services, hindering the needed investments for the new season. Therefore, governments should provide access to agricultural finance in the form of subsidized credit facilities to support smallholder farmers' investments in irrigation activities, thereby, ensuring timeliness of agricultural operations.

\section{Increased investments in irrigated agriculture}

To reverse national and international downward trend in agricultural investments, it is important to ensure that irrigated agriculture is centrally placed within overall development strategies. A lack of coordination between government departments, mainly those responsible for water resources and those responsible for agriculture, can hamper irrigation development, making public investments less effective. The joint efforts of all department involved should be translated into national investment portfolio on irrigated agriculture. A long-term irrigation development can be boosted by investing in infrastructure rather than in on-farm measures, especially roads, to reduce transportation costs and facilitate the access to markets and agro-inputs. 


\section{Conclusion}

There is no single blanket strategy to enhance crop WP in Burkina Faso, Morocco and Uganda, nor in any other country. Several policy instruments based on the above drawn recommendations may be implemented, acting in a complementary way and having relevant impacts on the economic growth beyond crop WP itself. Building on the assessment performed in the project pilot irrigation schemes, this document highlights some of the policy actions that could optimize crop water productivity, thus, strengthen food security and contribute to poverty alleviation. The ultimate goal of the policy instruments presented here is to create an enabling environment that allows the optimization of farming practices aimed at increasing crop water productivity as much as at improving livelihoods in rural areas. 


\section{Bibliography}

African Union (AU). 2016. CAADP Guidelines - Country impleme ntation under the Malabo Declaration https://au.int/sites/default/files/documents/31251-doc-the_country_caadp_ implementation_guide_-_version_d_05_apr.pdf

African Union (AU). 2014. Malabo Declaration on Accelerated Agricultural Growth and Transformation for Shared Prospe rity and Improved Livelihoods: http://www.resakss.org/sites/ default/files/Malabo\%20Declaration\%20on\%20Agriculture_2014_11\%2026-.pdf

Bin, S. 2009. La vallée du Sourou (Burkina Faso), entre agrobusiness et autonomie locale. Géocarrefour, 84(1-2), 73-82.

Comprehensive Africa Agriculture Development Programme (CAADP). 2018. - Community of Practice I (2018) [online]: http://www.nepad.org/cop/comprehensive-africa-agriculturedevelopment-programme-caadp

Direction générale des aménagements et du développementde l'irrigation. (DGADI) 2012. Rapport bilan de la campagne agricole de saison sèche 2011-2012. Ministère de l'Agriculture et de l'Hydraulique, Direction générale des aménagements et du développement de l'irrigation.

\section{Direction Générale de la Promotion de l'Economie Rurale (DGPER)}

2012. Résult ats définitifs de la campagne agricole et de la situation alimentaire et nutritionnel 2011-2012. Ministère de l'Agriculture et de l'Hydraulique, Direction Générale de la Promotion de l'Economie Rurale.

Doukkali, M. 2005. Water institutional reforms in Morocco. Water Policy, 7(1), 71-88.

FAO. 2002. International Rice Commission Newsletter Vol. 51 Gallagher, K. D., Ooi, P. A. C., Mew, T. W., Borromeo, E., \& Kenmore, P. E. Integrated pest management in rice. IRC Newsletters, 51, 9-23.

FAO. 2011. The State of the World's Land and Water Resources for Food and Agriculture. Managing systems at risk. Rome, Italy.

FAO. 2012. Who invests in agriculture and how much? An empirical review of the relative size of various investme nts in agriculture in low- and middle-income countries. ESA Working paper No.12-09

FAO. 2012a. The State of Food and Agriculture: Investing in agricultu re for a better future. Rome, Italy. 
FAO. 2012b. Rapport de capitalisation des acquis du Projet pilote d'économie et de valorisation de l'eau d'irrigation dans le périmètre des Doukkala (GCP/MOR/033/SPA). Rome, Italy.

FAO. 2013. FAO Statistical Yearbook. World food and agriculture. Rome, Italy.

FAO. 2014a. The State of Food and Agriculture: Innovation in family farming. Rome, Italy.

FAO. 2014b. Analysis of public expenditure in support of food and agriculture in Uganda, 2006/07-2012/13. Technical notes series, MAFAP, by Shinyekwa, I., Katunze, M. and Ahmed, M., Rome.

FAO. 2016a. The State of Food and Agriculture: Climate change, agriculture and food security. Rome, Italy.

FAO. 2016b. Migration, Agriculture and Rural Development. Addressing the root causes of migration and harnessing its potential for development. Rome, Italy.

FAO. 2017a. The future of food and agriculture, Trends and challenges. Rome, Italy

FAO. 2017b. Water for Sustainable Food and Agriculture. A report produced for the G20 Presidency of Germany. Rome, Italy.

FAO. 2018. The future of food and agriculture, Alternative pathways to 2050. Rome, Italy.

FAO. 2019. How to feed the world 2050. High-level Expert Forum. in Global agriculture towards 2050. Rome, Italy.

FAO. "AQUASTAT," 2016. [Online]. Available at: http://www.fao.org/nr/water/aquastat/water_use/ index.stm

FAO. “FAOSTAT," 2019. [Online]. Available: http://www.fao.org/faostat/en/\#home

Gouvernement du Burkina Faso. 2010. Country Compact: http://www.nepad.org/sites/default/ files/Burkina-Faso.pdf

Gouvernement du Burkina Faso. 2004. Stratégie de Développement Rural:. http://www.interreseaux.org/IMG/pdf_DSDR_definitif.pdf

Gouvernement du Burkina Faso. 2009. Programme National d'Investissements Agricoles (PNIA): http://www.grain.org/attachments/2690/download

Gouvernement du Burkina Faso. 2015. Politique Nationale de l'Eau: https://www.pseau.org/ outils/ouvrages/mea_politique_nationale_de_I_eau_2016_2030_2015.pdf 
Government of Uganda. 2013. Nutrition Country Paper: http://www.fao.org/fileadmin/user_ upload/wa_workshop/ECAfrica-caadp/Uganda_NCP_190213.pdf

Government of Uganda. 2013. National Agriculture Policy: http://agriculture.go.ug/wp-content/ uploads/2019/04/National-Agriculture-Policy-1.pdf

Government of Uganda. 2018. Statistical Abstract 2018. Uganda Bureau of Statistics: https:// www.ubos.org/wp-content/uploads/publications/05_2019STATISTICAL_ABSTRACT_2018.pdf

Government of Uganda. 2017. The Uganda Green Growth Developme nt Strategy 2017/18 - 2030/31: https://www.ndcs.undp.org/content/dam/LECB/docs/pubs-reports/undp-ndc-spuganda-ggds-green-growth-dev-strategy-20171204.pdf

High Level Panel of Experts on Food Security and Nutrition of the Committee on World Food Security (HLPE). 2013. Investing in smallholder agriculture for food security. A report by the High Level Panel of Experts on Food Security and Nutrition of the Committee on World Food Security, Rome.

High Level Panel of Experts on Food Security and Nutrition of the Committee on World Food Security (HLPE). 2015. Water for food security and nutrition. A report by the High Level Panel of Experts on Food Security and Nutrition of the Committee on World Food Security, Rome.

International Rice Research Institute (IRRI) 2019. Pests and diseases management. [Online]. Available at: http://www.knowledgebank.irri.org/training/fact-sheets

Jahn, G. C., Litsinger, J. A., Chen, Y., \& Barrion, A. T. (2006). 15 Integrated Pest Management of Rice: Ecological Concepts.

Kjær, A. M., \& Joughin, J. 2012. The reversal of agricultural reform in Uganda: ownership and values. Policy and Society, 31(4), 319-330.

Kijne, J. W., Barker, R., \& Molden, D. J. (Eds.). 2003. Water productivity in agricultu re: limits and opportunities for improvement (Vol. 1). Cabi.

Kijne, J. W. 2003. Unlocking the Water Potential of Agriculture. FAO, Rome, Italy.

Monitoring African Food and Agricultural Policies (MAFAP). 2013a. Revue des politiques agricoles et alimentaires au Burkina Faso. Série rapport pays SPAAA, FAO. Rome, Italie.

Monitoring African Food and Agricultural Policies (MAFAP). 2013b. Review of food and agricultural policies in Uganda. MAFAP Country Report Series, FAO, Rome, Italy.

Molden, D., Oweis, T. Y., Pasquale, S., Kijne, J. W., Hanjra, M. A., Bindraban, P. S. 2007. Pathways for increasing agricultural water productivity (No. 612-2016-40552). 
Ministère de l'agriculture, de l'hydraulique et des ressources halieutiques du Burkina Faso. 2011. Cadre d'action pour l'investisseme nt agricole au Burkina Faso: http://www.oecd.org/fr/ pays/burkinafaso/47860248.pdf

Ministère de l'Agriculture, de la Pêche Maritime, du Développement Rural et des Eaux et Forêts - Maroc: http://www.agriculture.gov.ma/pages/la-strategie

Ministère de l'Agriculture, de la Pêche Maritime, du Développement Rural et des Eaux et Forêts - Maroc. 2019. Agriculture en Chiffres 2018: http://www.agriculture.gov.ma/pages/ publications/agriculture-en-chiffres-2018-edition-2019

Mwamakamba, S. N., Sibanda, L. M., Pittock, J., Stirzaker, R., Bjornlund, H., Rooyen, A. v., Munguambe, P., Mdemu, M. V., Kashaigili, J. J. 2017. Irrigation Africa: policy barriers and oppo rtunities for enhanced productivity of smallholder farmers. International Journal of Water Resources Development, vol. 33(5).

OECD-FAO. 2016. Agricultu ral Outlook 2016-2025. Agriculture in Sub-Saharan Africa: Prospects and challenges for the next decade.

New Partnership for Africa's Development (NEPAD). 2009. Sustainable Land and Water Management: The CAADP Pillar 1 Framework: http://www.nepad.org/resource/sustainableland-and-water-management-caadp-pillar-i-framework

Ripama W., E. 2015. La Vallée du Sourou: acquis et perspe ctives. Niassan, Burkina Faso.

Uganda Ministry of Agriculture, Animal Industry and Fisheries (MAAIF). 2013. National Agriculture Policy: http://agriculture.go.ug/policies/

Uganda Ministry of Agriculture, Animal Industry and Fisheries (MAAIF) with the New Partnership for Africa's Development (NEPAD). 2003. Comprehensi ve Africa Agriculture Development Programme (CAADP): http://agriculture.go.ug/wp-content/uploads/2018/06/ Comprehensive-Africa-Agriculture-Development-Programme-CAADP.pdf

Uganda Ministry of Agriculture, Animal Industry and Fisheries (MAAIF) with International Food Policy Research Institute (IFPRI). 2009. CAADP Brochure 1: http://www.resakss.org/ sites/default/files/pdfs//uganda-caadp-brochure-1-what-does-a-caadp-compact-42549.pdf

UNESCO-ONGAWA. (2016) Lderechos humanos al agua potable y al saneamiento en la Agenda 2030. [Online]. Available at: http://www.unescoetxea.org/dokumentuak/dossier_agua_agenda2030.pdf

Wichelns D. 2014 . Do Estimates of Water Productivity Enhance Understanding of Farm-Level Water Management? Water; 6(4):778-795. 
World Bank (WB). 2016. The cost of irrigation water in the Jordan Valley. By Berg, van den C., Agha Al Nimer, S. KH. H. Washington, DC. License: Creative Commons Attribution CC BY 3.0 IGO 


\section{Policy guide to improve water productivity in small-scale agriculture}

\section{The case of Burkina Faso, Morocco and Uganda}

In developing countries, further progress of irrigation is essential for increasing food security and farmers' income. However, developing small-scale schemes remains a challenge due to the multiple factors that must be taken into consideration. The high diversity of small-scale schemes, the large number of water users, the social disharmony over water use, the varying water demands of multi-cropping systems and the heterogeneity of equipment over the scheme all represent relevant issues influencing the development of small-scale irrigation systems. Furthermore, on-farm irrigation development has a major role in enhancing Agricultural Water Management (AWM), beyond improving the conveyance system. The previous development methods considered the improvement of single-factor productivity. Agriculture is currently undergoing a global shift from the single objective of farming outputs (such as yield or net income) to multiple objectives of increasing outputs while conserving natural resources.

Many pathways towards the enhancement of Water Productivity (WP) are directly related to improving overall farm agronomic management (irrigation, fertilization, plant density, plant protection, etc.), while external measures must be taken into consideration to ensure the sustainability of introduced good practices (lack of input markets, scarce knowledge, poor condition of infrastructures, water regulations, etc.). Thus introducing irrigation practices to farmers must undergo a step-wise process to ensure that costs do not outweighed achievable benefits, and both institutional and technical environment are capable to sustain results. This is the case in smallholders' schemes in particular, where farmers are poorly resourced and access to relevant information is cumbersome. In order to address these issues, the current policy guide presents a combined methodology, which involves practical experiences drawn from FAO work in the three countries as well as researches' results to line up a set of feasible measures to improving WP.

Schweizerische Eidgenossenschaft

Confédération suisse

Confederazione Svizzera

Confederaziun svizra

Swiss Agency for Development and Cooperation SDC
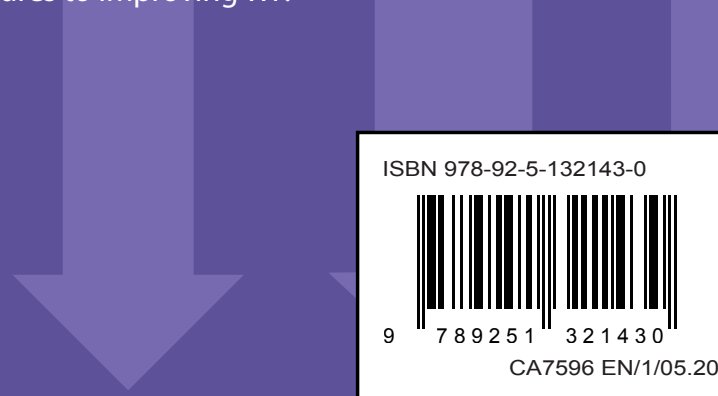